Cahiers de recherches médiévales

Journal of medieval studies

$8 \mid 2001$

La protection spirituelle au Moyen Âge

\title{
Les ordres religieux et le manteau de Marie
}

\section{Dominique Donadieu-Rigaut}

\section{(2) OpenEdition}

Journals

Édition électronique

URL : https://journals.openedition.org/crm/391

DOI : $10.4000 / \mathrm{crm} .391$

ISSN : $1955-2424$

Éditeur

Honoré Champion

Édition imprimée

Date de publication : 15 janvier 2001

Pagination : 107-134-xiv

ISSN : 1272-9752

\section{Référence électronique}

Dominique Donadieu-Rigaut, « Les ordres religieux et le manteau de Marie », Cahiers de recherches médiévales [En ligne], 8 | 2001, mis en ligne le 13 mars 2008, consulté le 15 décembre 2022. URL : http://journals.openedition.org/crm/391 ; DOl : https://doi.org/10.4000/crm.391

Ce document a été généré automatiquement le 15 décembre 2022.

Tous droits réservés 


\title{
Les ordres religieux et le manteau de Marie ${ }^{1}$
}

\author{
Dominique Donadieu-Rigaut
}

1 Depuis l'étude fondamentale de Paul Perdrizet, La Vierge de Miséricorde², parue en 1908, il semble communément admis de considérer comme synonymes les expressions Vierge au manteau et Vierge de Miséricorde. Cet amalgame provient d'une approche strictement iconographique des représentations envisageant le vaste pallium ouvert comme un "motif $"^{3}$ dont la sémantique demeure immuable, quelle que soit la communauté abritée sous le textile virginal. Or, les liens entre la micro-société gravitant autour de la Vierge et l'immense figure mariale se chargent de connotations se modifiant avec la nature du groupe abrité. La fonction protectrice de la Mater Dei ne doit donc pas être posée a priori mais au contraire déconstruite afin de ménager un espace à la polysémie de ces images et à leur variabilité. Aussi, il n'est pas indifférent que se blotissent sous le manteau de Marie tous les «status » de la société ou bien les seuls ordres religieux dont la cohérence spécifique repose avant tout sur des relations de parenté spirituelle.

2 Les premières représentations de la Vierge abritant un ordre sous son manteau se rencontrent en milieu cistercien, assez tardivement, durant le premier tiers du $\mathrm{XIV}^{\mathrm{e}}$ siècle. Elles se multiplient au cours de la seconde moitié du siècle pour se généraliser après 1400, affectant alors d'autres ordres, monastiques ou mendiants. Paul Perdrizet,dans l'ouvrage précédemment cité, attribue "1'invention » de ce thème iconographique aux Cisterciens, les Dominicains, puis les autres ordres religieux s'en étant emparé par la suite. En poursuivant une logique évolutionniste "d'élargissement» et de "laïcisation », l'auteur soutient que la formule se serait appliquée progressivement aux confréries et enfin à la société tout entière venant se blottir à son tour sous le pallium de la Mater omnium. Dans cette perspective, c'est le schéma élaboré par et pour les ordres qui aurait servi in fine de modèle à l'ensemble de la société, figurée dans sa diversitas. Les confréries, situées à la charnière des mondes laïque et religieux, auraient joué le rôle de maillon de transmission entre la figuration des ordres et celle de la société. 


\section{Le récit de Césaire de Heisterbach: une image qui ordonne et hiérarchise la société des Élus}

3 Cette démonstration repose en fait non sur une image mais sur une visio, celle d'un cistercien anonyme, relatée dans le Dialogus Miraculorum, un recueil de 746 exempla rédigé entre 1217 et 1222 par un autre moine blanc, Césaire de Heisterbach ${ }^{4}(\dagger 1210)$. L'ouvrage vise comme il se doit à glorifier l'ordre cistercien. Le livre VII, entièrement consacré à la Vierge Marie, contient au dernier chapitre le récit qui nous intéresse, intitulé De monacho qui ordinem cisterciensem sub Mariae pallio vidit in regno caelorum :

Un moine de notre ordre, qui avait une dévotion particulière pour Notre-Dame, fut, il y a quelques années, ravi en esprit, et admis à contempler le ciel de gloire. Ayant vu les divers ordres (ordines) de l'Église triomphante, les Anges, les Patriarches, les Prophètes, les Apôtres, les Martyrs, les Confesseurs, et, répartis selon leurs insignes, 1es Chanoines Réguliers, les Prémontrés, les Clunisiens, il s'inquiéta de son ordre à lui (de suo ordine). Et il regardait de tous côtés, et ne découvrait aucun des siens dans le Royaume de Gloire. Alors se tournant vers la bienheureuse Mère de Dieu, il gémit et lui dit: "Pourquoi donc, Dame très sainte, ne vois-je ici personne de Cîteaux? Pourquoi les plus dévoués de vos serviteurs sont-ils exclus de ces béatitudes ?" Et la Reine du Ciel lui répondit: "Ceux de Cîteaux me sont au contraire si chers et si familiers que je les réchauffe sous mes bras" (sub ulnis meis foveam). Et ouvrant le manteau (pallium) qui la couvrait et qui était d'une largeur merveilleuse, elle lui montra une multitude innombrable de moines (innumerabilem multitudinem monachorum), de frères convers et de nonnes. Lui, plein d'une grande joie, rendit grâces, et son esprit ayant réintégré son corps, il raconta à son abbé ce qu'il avait vu et entendu ${ }^{5}$.

Cette vision, dont le dessein spirituel est bien sûr de présenter Marie comme la protectrice spéciale d'un ordre cistercien parfait, offre également un intérêt anthropologique: celui de hiérarchiser des catégories en les spatialisant dans le paysage céleste. Le « ciel de gloire »contient en effet non seulement les « divers ordres (ordines) de l'Église triomphante", c'est-à-dire les groupes constitutifs des cours célestes, depuis les Anges jusqu'aux Confesseurs, mais aussi les divers ordres religieux (ordines) en présence à l'époque, en l'occurence les Chanoines Réguliers, les Prémontrés et les Clunisiens ${ }^{6}$. Ordo manifeste ici un de ses champs sémantiques les plus récurrents, celui du module qui ne prend sens que compris dans une série ordonnée plus vaste. Aussi les ordres religieux se trouvent-ils intrinsèquement liés à l'ensemble des ordines de l'Église spirituelle.

5 La description du Ciel de Gloire livrée par le moine blanc s'avère très proche des images «matérielles » de cours célestes ${ }^{7}$ organisant les Élus en couronne autour de la Trinité, du couronnement de la Vierge, ou bien encore derrière les remparts idéaux de la Cité de Dieu ${ }^{8}$. Cependant, dans ces représentations de la Concorde paradisiaque, les ordres religieux n'apparaissent jamais en tant que groupes constitués collectivement élus. Fonctionnant à partir des catégories traditionnelles de la sainteté ${ }^{9}$, les cours célestes figurent généralement les ordres à travers leur saint fondateur. Par exemple, dans le Couronnement de la Vierge d'Enguerrand Quarton ${ }^{10}$ (1453-54), une rangée est réservée aux pères spirituels des ordres, individuellement sanctifiés. C'est à ce titre que Jean Gualbert, Bernard, François et Dominique prennent place dans le concert des Élus, entre les diacres et les grands de ce monde. Même si, à travers la figure auréolée du saint fondateur, c'est l'ordre tout entier qui se trouve implicitement associé à la gloire, 
l'image ne cherche pas à mettre spécialement en valeur la dimension collective de l'ordo.

6 Or, dans la vision rapportée par Césaire de Heisterbach, ce sont les membres assemblés qui représentent leur ordre, sans que mention soit faite d'un quelconque fondateur. Le Tout n'est donc pas incarné par la figure métonymique du père spirituel. Au contraire, les divers ordines, micro-sociétés célestes, se différencient les uns des autres par leurs signes distinctifs, conférant à chacun une identité de groupe (... et eosdem certis characteribus distinctos, item Canonicos Regulares, Praemonstratenses, sive Cluniacenses...).

7 C'est donc l'ensemble de la société des Élus qui est révélé au Cistercien, une société divisée en plusieurs cellules collectives parmi lesquelles les ordres religieux, constitués chacun par la réunion de leurs membres, tiennent une place de choix.

8 Néanmoins, les Moines Blancs n'occupent pas directement un de ces quartiers spécifiques de la Cité céleste. Ils se lovent dans un sous-compartiment, l'ample manteau de la Vierge, délimitant un locus particulier à l'intérieur même de l'Église triomphante. Le texte ne stipule pas si Marie se trouve intégrée au noyau trinitaire ou bien en position d'Elue des élus, et donc à la tête de la société des saints. Quoi qu'il en soit, les Cisterciens habitent au plus près du sanctus sanctorum, dans un espace intermédiaire entre le corps virginal qui a engendré le Fils et un tabernaculum textile proche de l'extension corporelle.

9 Là encore, sous le manteau de Marie, l'ordo cisterciensis est représenté par la somme de ses membres et non emblématisé par l'effigie du fondateur. Le récit va jusqu'à distinguer à l'intérieur même de la famille religieuse trois sous-ensembles, celui des moines, des frères convers et des nonnes, instaurant ainsi un ultime classement au sein de la congregatio.

10 L'intérêt fondamental de ce texte réside donc dans le fait qu'il manifeste d'emblée la dimension sociale de la Vierge au Manteau, dans la mesure où celle-ci abrite un ordo constitué de la multitude ordonnée de ses membres, eux-mêmes en relation avec un Tout plus vaste, le ciel de Gloire, contenant Marie, et organisant par catégories collectives l'ensemble des élus.

11 La vision rapportée par Césaire de Heisterbach, bien qu'étant retenue par $P$. Perdrizetcomme premier spécimen d'une "Vierge de Miséricorde» appliquée à un ordre religieux, n'en est en fait pas une. En effet, si Marie « réchauffe sous ses bras » les moines, les convers et les moniales, qui lui sont «si chers et si familiers » (dilecti ac familiares), elle ne les protège nullement d'une quelconque colère divine puisque l'ordre cistercien est ici présenté comme le sommum de la perfection ${ }^{11}$. Le fait d'être enveloppé dans le manteau de la Vierge, tout contre le réceptacle du Verbe Incarné, constitue au contraire un insigne privilège, un signe d'élection plus que de protection. L'ordre cistercien accède alors à une sorte d'équivalent «très spécial » de la vision béatifique, qui ne passerait pas par le regard spirituel des corps glorieux pouvant voir Dieu « face à face »,mais plutôt par le contact corporel direct avec le « vase $»^{12}$ qui a donné chair au Verbe. Bien que l'ordre cistercien ne soit ni inscrit ni inclus dans le corps de Marie, strictement réservé au Rédempteur, il le frôle et le côtoie, goûtant ainsi sa chaleur ${ }^{13}$. Le manteau délimite donc un espace ambigu qui n'est pas tout à fait l'intérieur du corps, mais qui relève somme toute de la membrane, c'est-à-dire de la limite corporelle laissant pressentir la substance nucléaire. Ainsi, comme une seconde enveloppe qui 
« réchauffe » $(\text { foveam })^{14}$, le manteau dessine une zone de 1'entre-deux entre le dedans et le dehors, entre l'ardente sacralité de 1'uterus la froidure de 1'Extérieur.

En outre, le pallium,textile "corporéisé» refermé sur les moines, sanctifie la communauté dans la mesure où il la cache, à l'instar d'un reliquaire ou d'un ciborium dissimulant à la vue du tout-venant l'objet sacré ou consacré qu'il recèle. La récurrence des termes liés à la vue (videret, video, videns, videbatur, viderit), ainsi que la mise en scène du dévoilement et de l'ostentation des Cisterciens (Aperiensque pallium suum, ostendit), n'est pas sans rappeler le « désir de voir l'hostie ${ }^{15}$ qui se développe précisément au cours du XIII ${ }^{\mathrm{e}}$ siècle.

\section{Le sceau : creuset d'une réflexion sur l'expression de l'identité collective}

13 C'est également en milieu cistercien qu'apparaissent les premières représentations, entre 1320 et 1340 , donc un bon siècle après la rédaction de la visio par Césaire de Heisterbach. Cet écart temporel invite à relativiser le lien causal direct entre le texte et l'image, et à chercher d'autres interférences, plus structurelles que temporelles, ayant permis l'éclosion de ces représentations.

Parmi les trois premiers documents cisterciens, deux sont des sceaux ${ }^{16}$ : le sceau de l'Abbaye de Beaupré (sise en Lorraine), daté de 1335, et le sceau du définitoire de Cîteaux, c'est-à-dire de l'assemblée des définiteurs, petit groupe d'abbés désignés par l'abbé de la Maison-Mère pour veiller au bon déroulement du chapitre général. Le support de ces images n'est pas anodin. Il révèle le désir d'élaborer une formule iconique synthétique et reconnaissable qui puisse dire l'identité collective, exprimer la " personne morale » que forment les membres assemblés, c'est-à-dire quelque chose de plus que leur simple somme. Les sceaux ayant pour fonction première d'authentifier et de certifier un écrit, d'en révéler la provenance et d'en affirmer l'autorité, constituent des images auto-représentatives particulièrement denses dans la mesure où elles représentent, au sens fort du terme, la source émettrice à l'Extérieur. Pour reprendre les termes de Michel Pastoureau, «que le possesseur soit une personne physique ou une personne morale, son sceau est toujours sa seule image de lui-même qui circule, qui est vue de loin. Par là-même, tout sceau constitue une proclamation, une façon d'affirmer 'voilà qui je suis' $»^{17}$. Cette fonction acquiert une pertinence renforcée en milieu monastique ${ }^{18}$ car le sceau est la seule image auto-représentative de l'ordre et/ou de la communauté à transgresser la clôture; c'est le sceau qui véhicule la voix monacale de l'Intérieur vers l'Extérieur, soit à destination du monde (rompant alors le silence sans pour autant renier la frontière entre les Réguliers et le siècle), soit à destination d'autres maisons affiliées (renforçant alors les liens de parenté spirituelle à l'intérieur même d'un réseau donné).

15 Le sceau de l'abbaye de Beaupré19 (Doc. 1), rond, comprend sur son champ une Vierge frontale, légèrement hanchée, portant sur son bras gauche l'enfant Jésus et dans sa main droite un lys. Son manteau aux pans écartés abrite cinq moines agenouillés, en prière, les mains jointes (trois du côté du lys, deux de l'autre côté). De part et d'autre du corps axial de Marie, le pallium est maintenu allégoriquement soit par le végétal, soit par le petit bras de l'Enfant. Cette image, évoquant une sorte d'incorporation de la communauté dans la structure mariale, se trouve elle-même comprise dans une rosace 
polylobée, à son tour cernée par une inscription qui court en rond tout autour du sceau ${ }^{20}$. Le texte, qui clôt la représentation comme une enceinte, débute par une croisette qui en stigmatise le départ et en détermine le sens de lecture : $†$ s. conventus. BELLI. PRATI. CONSTITUTUM. ANNO. DOMINI. MCCCXXXV.

Doc. 1. Sceau de l'abbaye cistercienne de Beaupré (1335)

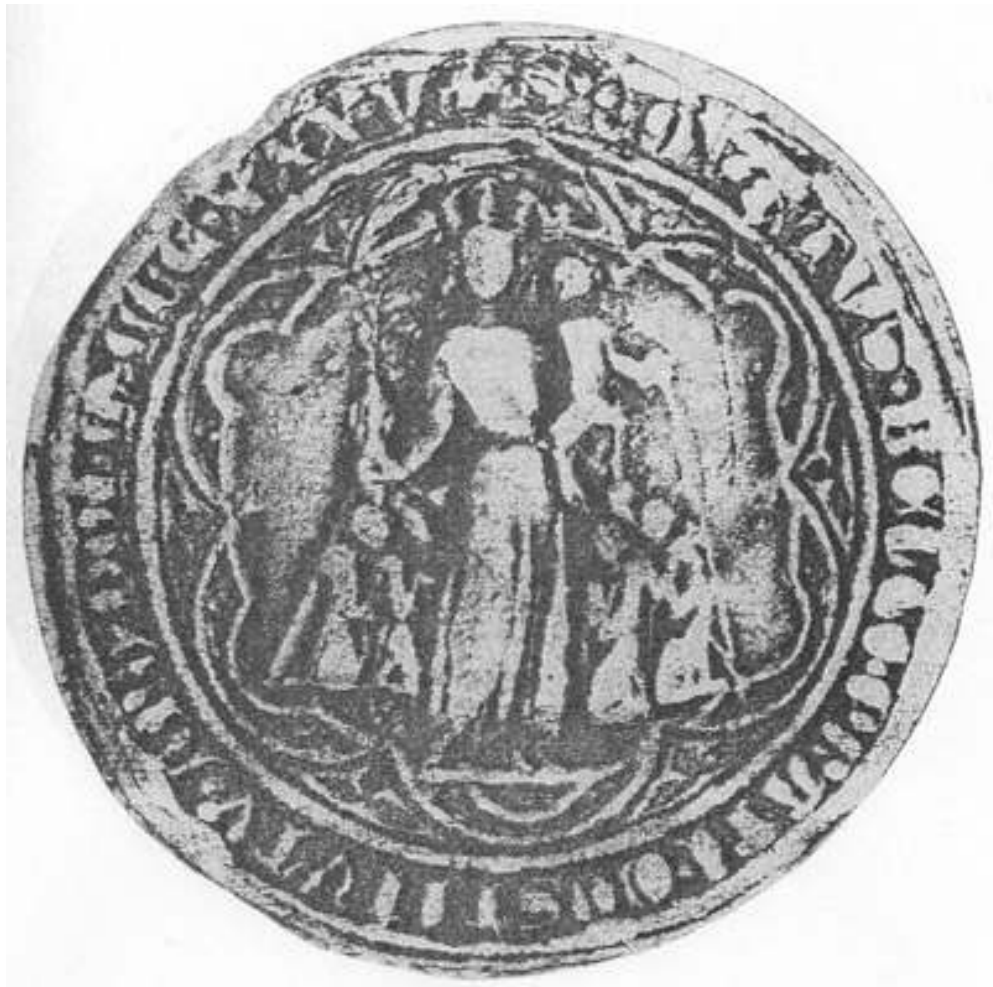

Archives départementales de Meurthe-et-Moselle, Nancy, B. 483, nº 12.

Il s'agit donc d'un sceau qui ne représente pas directement l'ordo cisterciensis mais une maison particulière du réseau cistercien. Cependant, le terme employé, conventus,ne désigne pas le couvent de Beaupré en tant qu'établissement matériel. Michaud-Quantin, dans sa belle étude intitulée Universitas ${ }^{21}$ (analysant les différentes formes de regroupement des hommes dans la société médiévale à partir du vocabulaire), a élucidé le sens précis de ce terme, lié précisément à l'exercice administratif et juridictionnel des communautés monastiques voulant émettre des actes à l'intention de l'extérieur.

Le principal emploi de conventus se rencontre dans les documents de la pratique : la formule courante des actes posés par une maison religieuse indique que leur auteur est le supérieur - abbas ou prior - et l'ensemble des membres - et conventus, cum conventu. L'idée ainsi exprimée est claire, montrer que c'est la communauté tout entière qui est concernée par l'événement, a la possession des biens en cause, est le sujet de droit dans l'affaire engagée (...) Lorsque l'on s'occupait de relations extérieures, plus encore d'actes d'administration temporelle, il était normal qu'un autre terme fût préféré (à celui de capitulum, réservé aux questions de discipline interne). Conventus, qui désignait lui aussi l'ensemble des moines, connotant le fait qu'ils s'étaient effectivement rassemblés pour prendre part à l'acte en cause, exprimait précisément cette idée de la communauté réunie autour de son chef et agissant collectivement avec lui ${ }^{22}$. 
17 Ainsi, si l'on suit la sémantique de conventus, l'idée mise en exergue par le sceau est celle d'une gestion commune des affaires, d'un mode de fonctionnement participatif de la communauté. L'acte certifié par ce sceau émane de l'unanimité des membres assemblés, exprime l'adhésion de tout le corps monastique.

18 Le second sceau ${ }^{23}$ (Doc. 2), utilisé durant la première moitié du XIV ${ }^{\mathrm{e}}$ siècle, figure un autre degré du pouvoir collectif, non plus au niveau d'une maison particulière mais de la congregatio tout entière. La collégialité n'en est pas moins mise en valeur puisque ce sont les définiteurs qui viennent se regrouper sous le manteau de la Vierge, comme l'indique l'inscription : S DIFFINITORUM CAP. LI GENERALIS CIST. ORDI.S. Ces abbés " experts », choisis par l'abbé de Cîteaux, avaient initialement pour tâche de mettre au point les textes à soumettre à l'assemblée lors du chapitre général, et de veiller à l'exécution de l'ordre du jour. Ils étaient donc responsables du bon fonctionnement du chapitre général ${ }^{24}$. À partir de la fin du XII ${ }^{e}$ siècle, l'ordre ayant atteint une dimension européenne, tous les abbés de toutes les maisons ne pouvaient plus matériellement se réunir chaque année à Cîteaux. Aussi, c'est un noyau d'abbés, le définitoire (comprenant les abbés des quatre premières filles de Cîteaux - La Ferté, Pontigny, Clairvaux et Morimond - assistés de quelques autres abbés tournant annuellement) qui concentra le pouvoir décisionnel. C'est à ce titre que le définitoire représente l'ordre. Les documents normatifs émanent de cette "autorité partagée » censée représenter l'ensemble de l'ordo. L'organe du pouvoir central ne se trouve donc pas incarné en une personne physique, Père tout puissant cristallisant entre ses mains les liens de dépendance rattachant tous les prieurés à un Seigneur unique (comme ce fut le cas à Cluny jusqu'à la réforme de Pierre le Vénérable, d'ailleurs inspirée par Cîteaux ${ }^{25}$ ). Au contraire, le sceau choisit de figurer le petit groupe d'abbés qui siègent chaque année à la MaisonMère afin d'harmoniser l'habitus des différents pôles constitutifs du réseau monastique $^{26}$. 


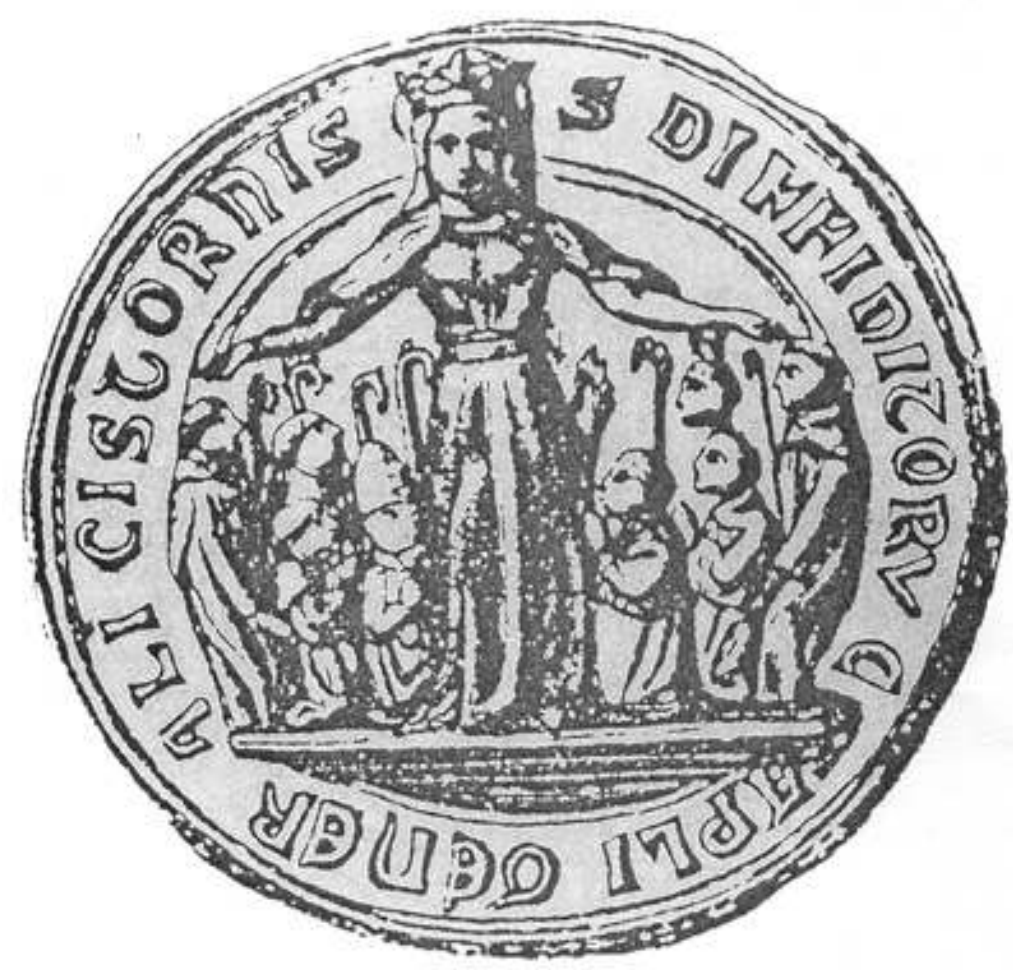

Sceau détruit, connu par un relevé.

19 Ainsi, la grande figure de la Vierge au manteau, qui étend ses bras au-dessus du groupe d'abbés (tenant tous en main l'insigne de leur fonction, la crosse), confère par son corps à la fois englobant et structurant une armature unitaire au principe de collégialité. Plus qu'un contenant passif, Marie figure ici le ciment d'une congregatio dépourvue de caput à son sommet, c'est-à-dire la caritas en tant que mode de fonctionnement spécifiquement cistercien. Qui mieux que la Vierge pouvait incarner ce désir fondamental d'Unanimité27 émanant davantage d'une dilectio réciproque que d'un pouvoir institutionnel personnalisé ?

À la fin du XIV ${ }^{\mathrm{e}}$ siècle (1393), le sceau de l'abbaye de Sainte-Hoïlde ${ }^{28}$ prouve que la formule peut également s'appliquer à une communauté de moniales (Doc. 3). La Vierge, immense, écartant les bras à l'horizontale, forme avec son pallium un véritable «carré ecclésial » dans lequel viennent se loger, en bon ordre, les moniales cisterciennes. À l'extérieur de cet espace clos géométrisé, de souples rinceaux remplissent le reste du champ évoquant ainsi la fertilité spirituelle de la communauté religieuse. 


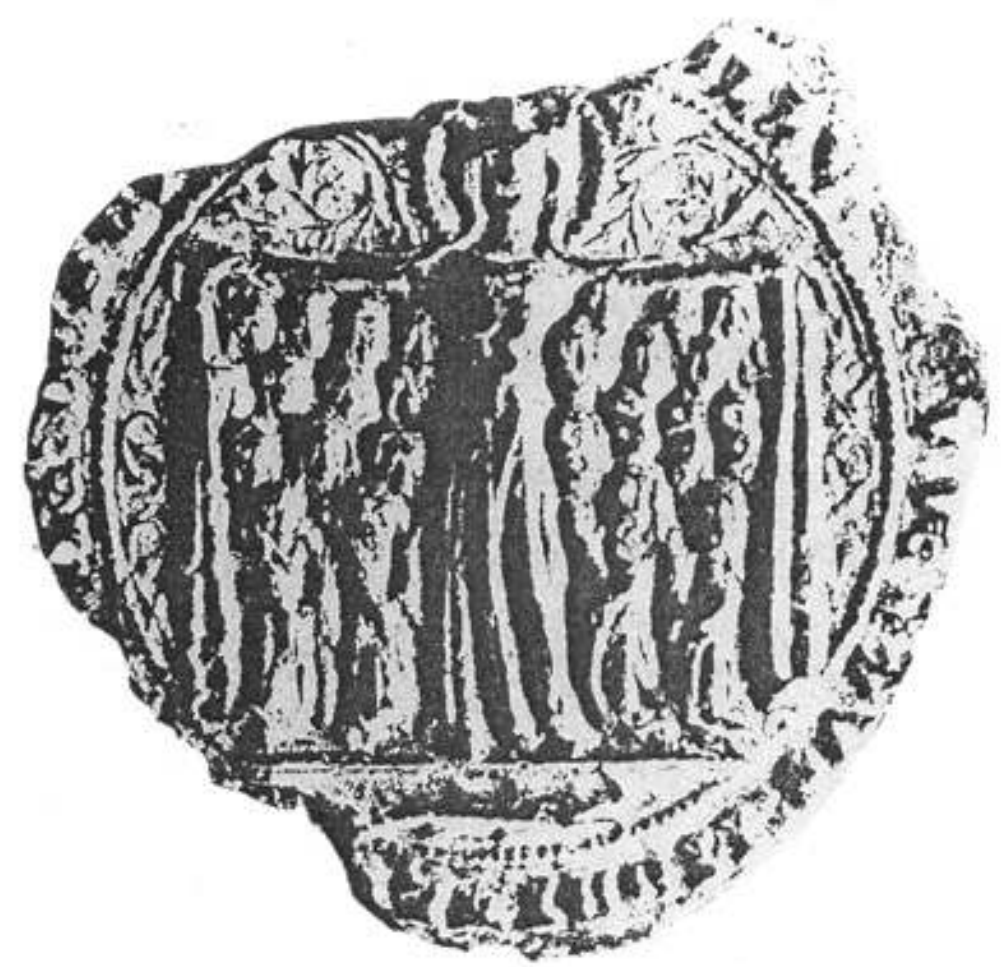

Archives départementales de Meurthe-et-Moselle, Nancy, B. 480, n 22.

21 On retrouve le même type de préoccupations dans les sceaux urbains qui cherchent à exprimer la personne morale que constitue le corps communal ${ }^{29}$. Dès la fin du $\mathrm{XII}^{\mathrm{e}}$ siècle, le sceau de la ville de Meulan (1195) offre le portrait collectif des échevins figurés par douze visages de face agencés sur trois rangées (Doc.4). Les nombres présidant à l'organisation de cette image (le 12 et le 3) laissent à penser que la frontière entre la figuration des groupes laïques et des groupes bibliques (en l'occurrence le collège des Apôtres) n'est pas totalement étanche. 
Doc. 4. Sceau de l'assemblée communale de Meulan (appendu à un acte de 1195)

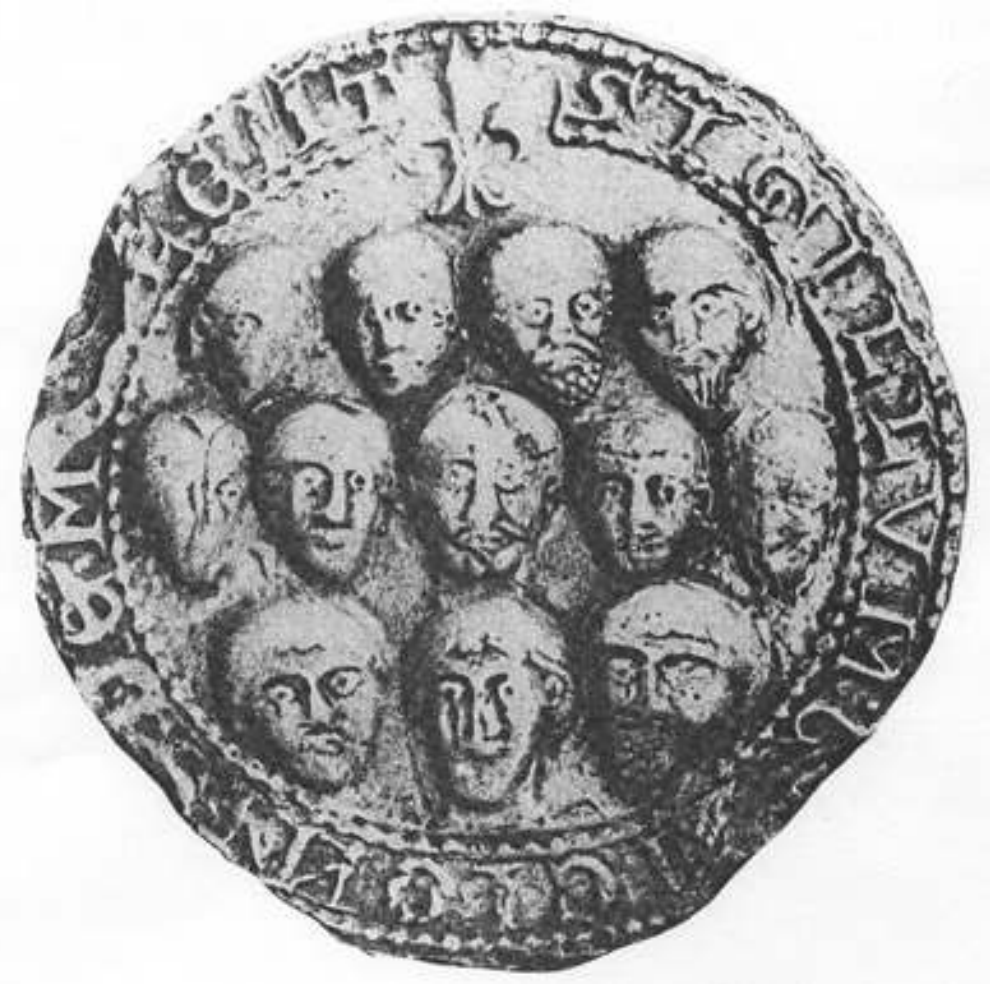

Moulage, Archives nationales, Paris, $n^{\circ} 1645$ lequel six personnages laïques, formant un collectif non hiérarchisé (ils sont tous assis à la même hauteur, sur le même banc), discutent deux à deux. Les toits de la ville figurés au-dessus d'eux (ou derrière eux ?) incarnent à la fois l'objet de leur débat, le cadre de leur action et la structure englobante qui confère au conseil son unité. 
Doc. 5. Grand sceau de Saint-Omer (appendu à un acte de 1299)

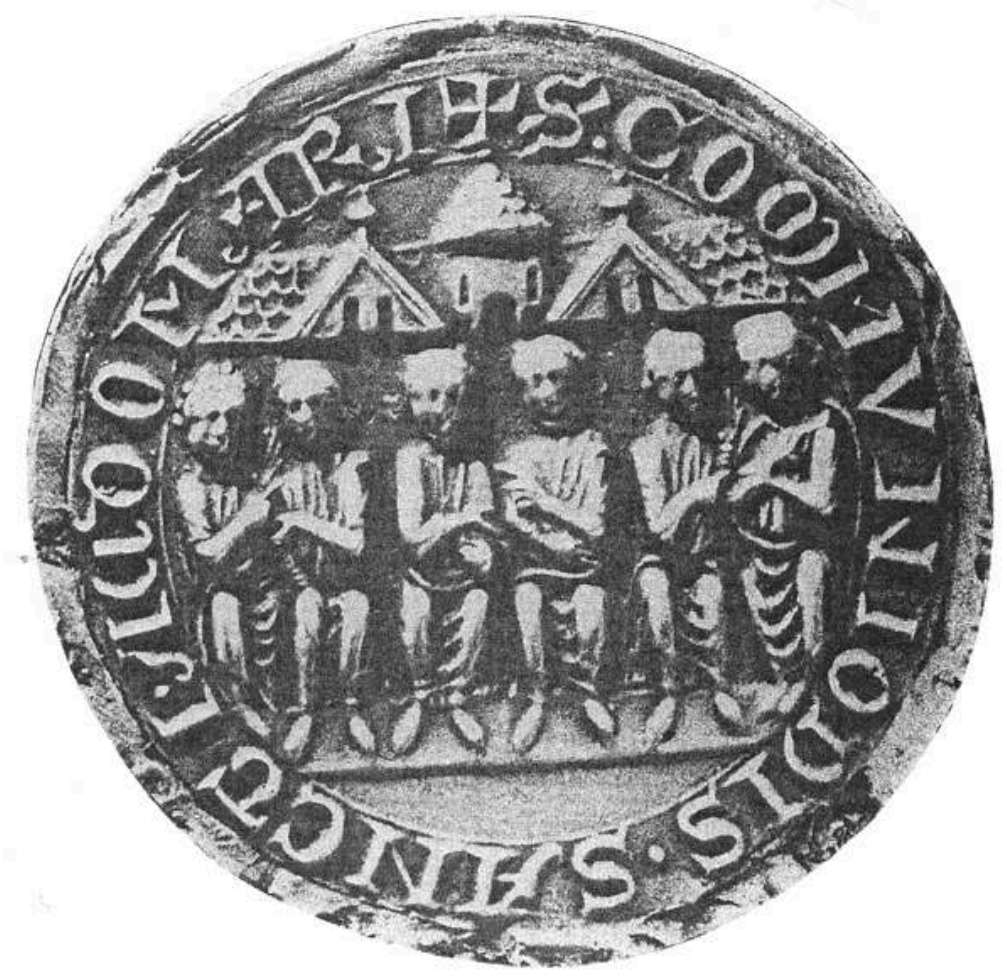

Moulage, Archives nationales, Paris, J. 574, $n^{\circ} 4^{7}$.

Doc. 6. Sceau de la ville de Dijon (1308)

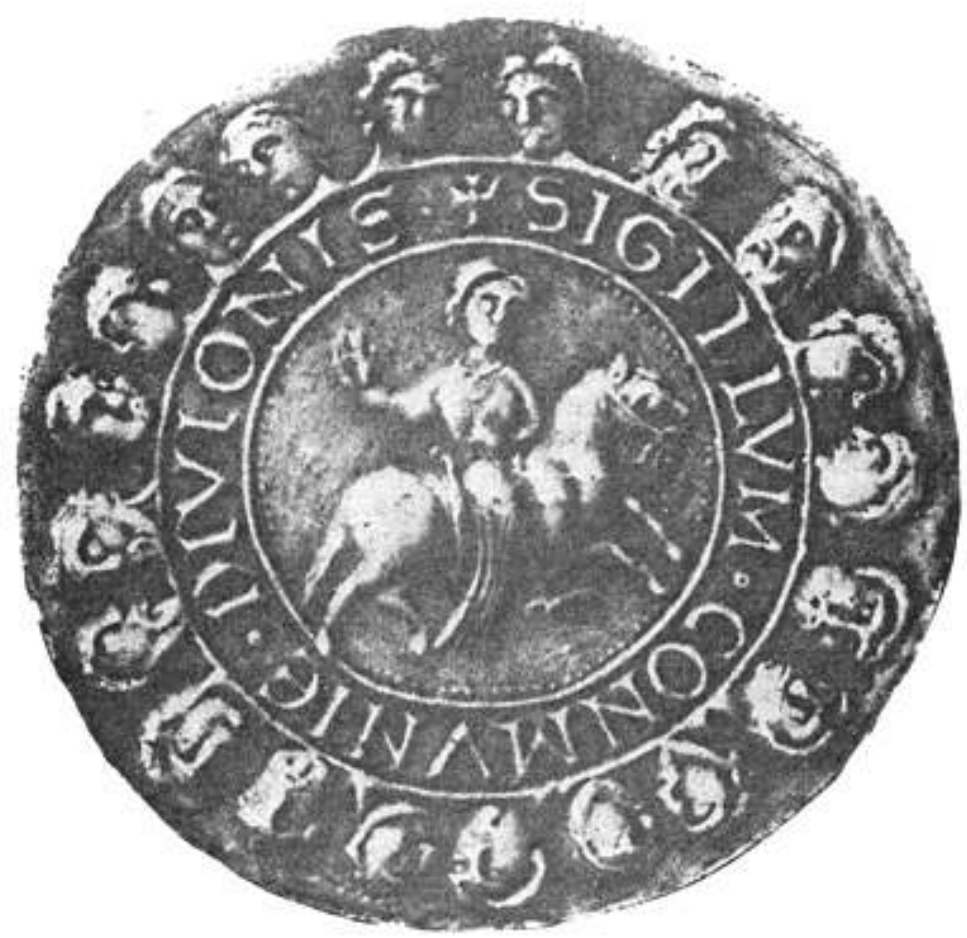

Paris, BnF, Cabinet des médailles et moulage Archives nationales, D. 5474. 
l'invention du thème de la Vierge au manteau par les Cisterciens à partir de la dévotion particulière que cet Ordre voue à Marie, un autre paramètre s'impose, plus anthropologique. En remettant à plat les sources, en décloisonnant les approches monographiques qui entérinent la césure a priori entre «iconographie religieuse » et "iconographie laïque ", il apparaît qu'un certain mode de fonctionnement collégial, remettant en cause le chef unique, a favorisé l'éclosion d'une image telle que la Vierge au Manteau abritant un Ordo. Ce n'est pas un hasard si l'ordre cistercien, vaste réseau d'abbayes mères et filles (les filles pouvant devenir mères à leur tour) dont la véritable tête est incarnée par le chapitre général, s'est fait l'initiateur de cette image ${ }^{31}$. Les structures institutionnelles de l'Ordre, moins hiérarchisées, plus décentralisées (tout au moins idéalement), requéraient un autre mode de figuration de l'Unité et de la Concorde, finalement assez proche de celui qui travaille les symboles sigillaires de la ville. Le fait que les sceaux cisterciens étudiés ci-dessus soient ronds comme ceux des communes, et non en navette comme la plupart des sceaux ecclésiastiques (qui dessinent une mandorle autour de la figure en pied de l'Autorité - évêque ou abbé -), confirme encore les préoccupations communes de l'ordre cistercien et de la cité : exprimer, par une imago emblématique et reconnaissable, la conscience qu'un corps collectif non-pyramidal a de lui-même.

\section{La Vierge, facteur de distinctio à l'intérieur de l'ordre}

Le grand corps de Marie, enveloppant l'Ordo dans son manteau, instaure ainsi la collégialité et l'unanimité chères aux Moines Blancs. Il dessine une frontière extérieure, ou plutôt une membrane textile, qui maintient unis en une caritas mutuelle les membres de la congregatio. Ce phénomène de resserrement autour du pôle virginal n'exclut cependant pas une certaine ordonnance à l'intérieur même de l'ordre. L'une des toutes premières images cisterciennes (contemporaine des sceaux étudiés) rend particulièrement sensible cette fonction organisatrice du corps de Marie. 


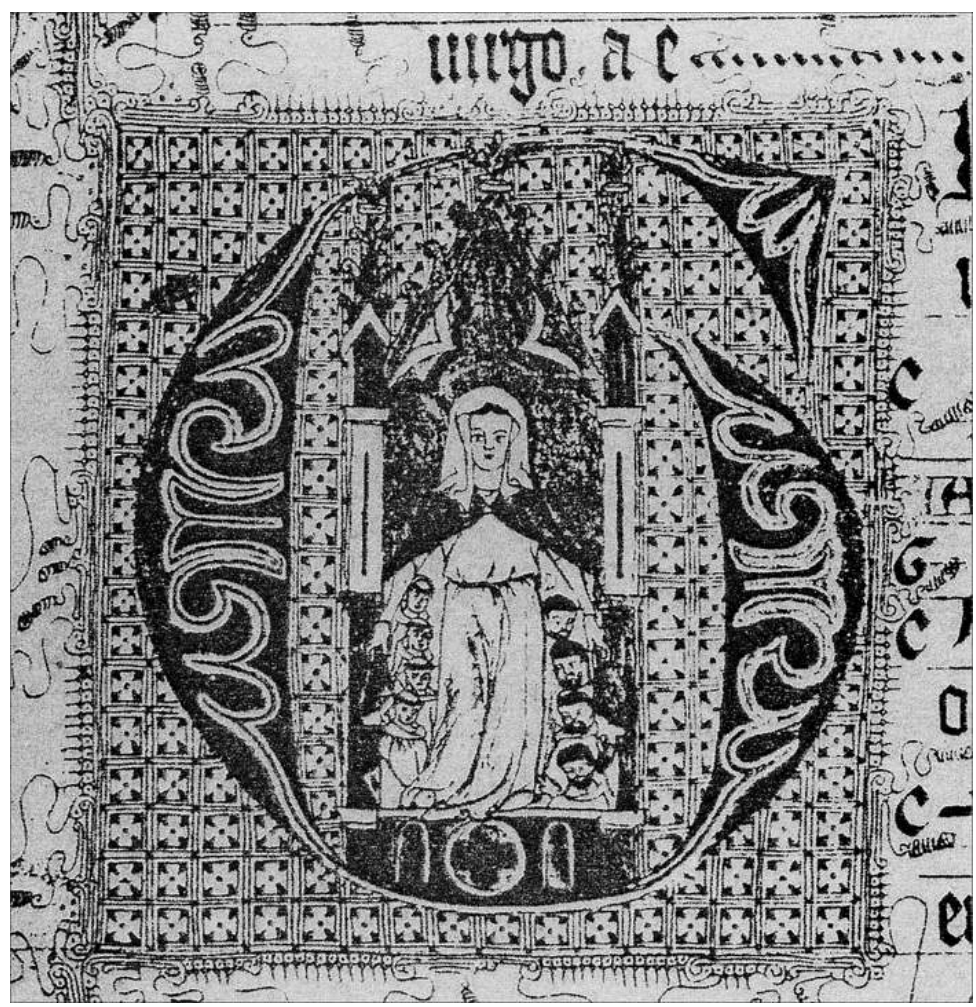

Wroclaw, Bibliothèque universitaire, ms IF 413, fol. 145.

Sur ce document, la Vierge au manteau est figurée dans une initiale historiée (le G de Gaudeamus) ornant le folio 145 du graduel de l'abbaye de Leubus (Doc. 7) ${ }^{32}$. Ce manuscrit liturgique, réalisé entre 1320 et 1330 , est aujourd'hui conservé à la bibliothèque universitaire de Wroclaw en Pologne (ms IF 413). Marie, elle-même inscrite dans un dais-édifice gothique, abrite huit personnages: quatre moines tonsurés à sa droite, quatre frères convers ${ }^{33}$, barbus, à sa gauche. L'espace que crée le manteau ouvert, tout en rassemblant la communauté, rend manifeste les catégories hiérarchiques internes à 1'Ordo. Le corps de Marie, donc, assume ici deux fonctions simultanées : il rassemble et ordonne tout à la fois. Cette fonction perdure jusqu'à la fin du Moyen Âge, puisqu'on la retrouve sur le frontispice d'un recueil de privilèges constitué par l'abbé de Cîteaux Jean de Cirey (Les Collecta privilegiorum ordinis cisterciensis), et imprimé à Dijon en 1491 par Petrus Metlinger ${ }^{34}$ (Doc. 8). La Vierge, écartant les pans de son manteau, révèle un ordre cistercien innombrable, à l'instar de la vision rapportée par Césaire de Heisterbach. La "foule monacale» est interrompue latéralement par le cadre de l'image (on imagine donc que la société cistercienne se prolonge hors champ), et vient se perdre de surcroît derrière le corps de Marie, à l'infini. Cette fois-ci, l'effigie de la Vierge opère la distinctio avant tout selon le paramètre des sexes, les moines se groupant à sa droite et les moniales à sa gauche. L'institution des convers apparaît alors comme une sous-catégorie de la zone masculine, uniquement représentée par l'un de ses membres, barbu et non tonsuré, qui émerge sous la main de Marie plissant son manteau. À l'inverse, le versant féminin, ordonné en rangées parallèles, se montre d'une homogénéité parfaite. 
Doc. 8. «Vierge au manteau des Cisterciens »

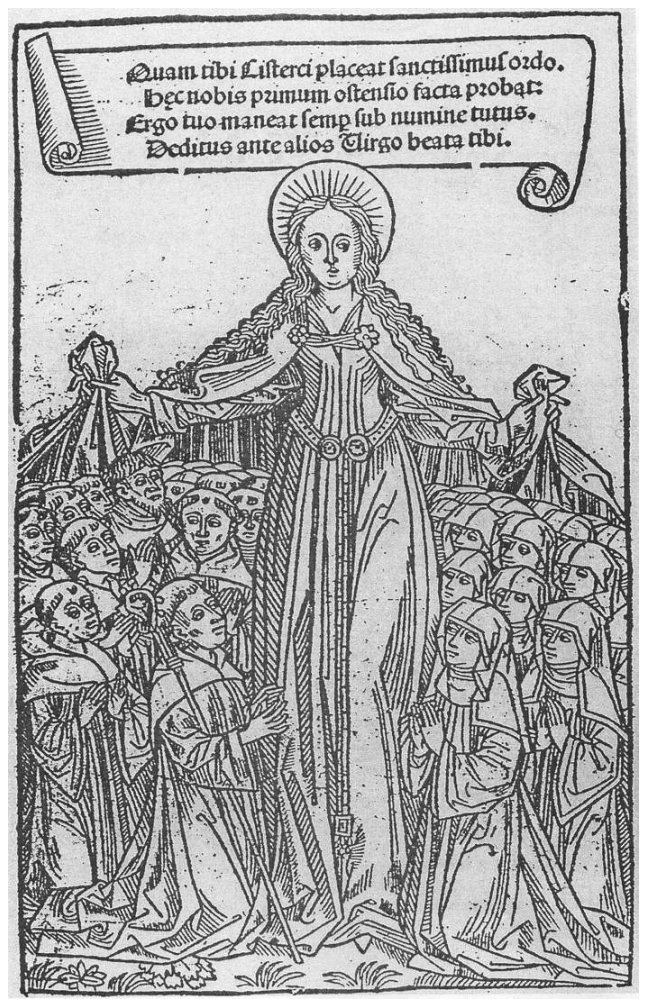

Gravure sur bois, extraite de Jean de Cirey, Collecta privilegiorum ordinis cisterciensis, Dijon, imprimeur Petrus Metlinger, 1491. Dijon, Bibliothèque municipale.

Cette partition du Tout en deux sous-ensembles selon les critères du masculin et du féminin ne se rencontre pas uniquement dans les représentations de la Vierge abritant les ordres monastiques. Lorsque la Vierge de Miséricorde protège la société tout entière, elle répartit la plupart du temps les laïcs en deux groupes de part et d'autre de son corps, les hommes à sa droite, les femmes à sa gauche (Doc. 9). 
Doc. 9. Vierge de Miséricorde

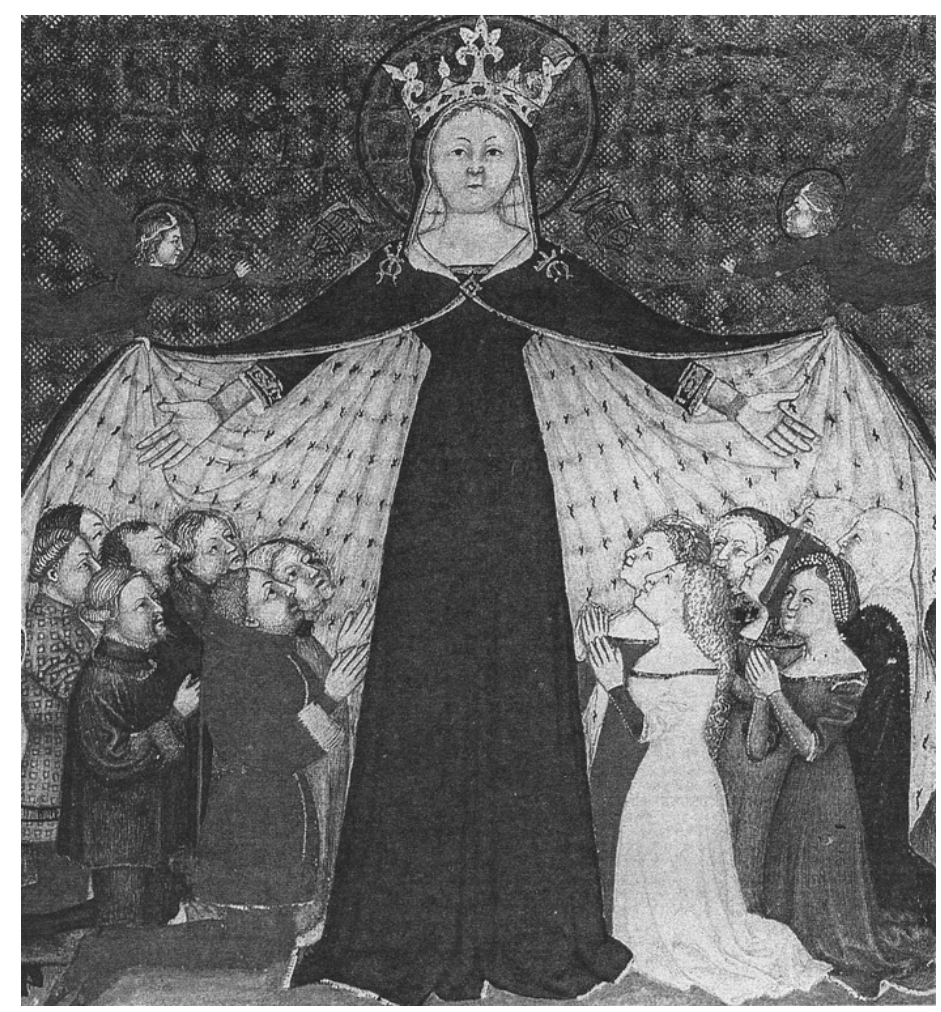

Missel et livre d'heures franciscain (1380), Paris, BnF, ms. lat. 757, fol. 251.

Cette partition correspond aussi à une hiérarchisation. En séparant les hommes des femmes, Marie leur assigne simultanément des places, et donc des rôles respectifs bien déterminés qui, malgré le caractère symétrique de l'image, ne sont pas interchangeables ${ }^{35}$ (même sur les gravures, qui ont pourtant tendance à inverser la droite et la gauche). En effet, il apparait vite, en comparant les images entre elles, que l'un des côtés est implicitement davantage valorisé que l'autre, aussi bien dans les représentations de la société que dans celles des ordres monastiques. La gente féminine, laïque ou religieuse, se trouve systématiquement à la gauche de la Vierge, tandis que les hommes (moines ou laïcs) prennent place à sa droite. Le même procédé d'agencement est repris lorsque la division s'appuie non plus sur des critères de genre, ni sur des facteurs hiérarchiques internes à la communauté religieuse, mais sur la césure culturelle essentielle entre clercs et laïcs ${ }^{36}$ (Doc. 10). Les gens d'Église (réguliers et séculiers confondus), agenouillés à la droite de la Vierge, s'opposent collectivement aux fidèles en prière de l'autre côté du corps marial, le Pape faisant ainsi face à l'Empereur. 
Doc. 10. Louis Brea, Vierge de miséricorde ou Vierge du Rosaire (fin du XVe siècle)

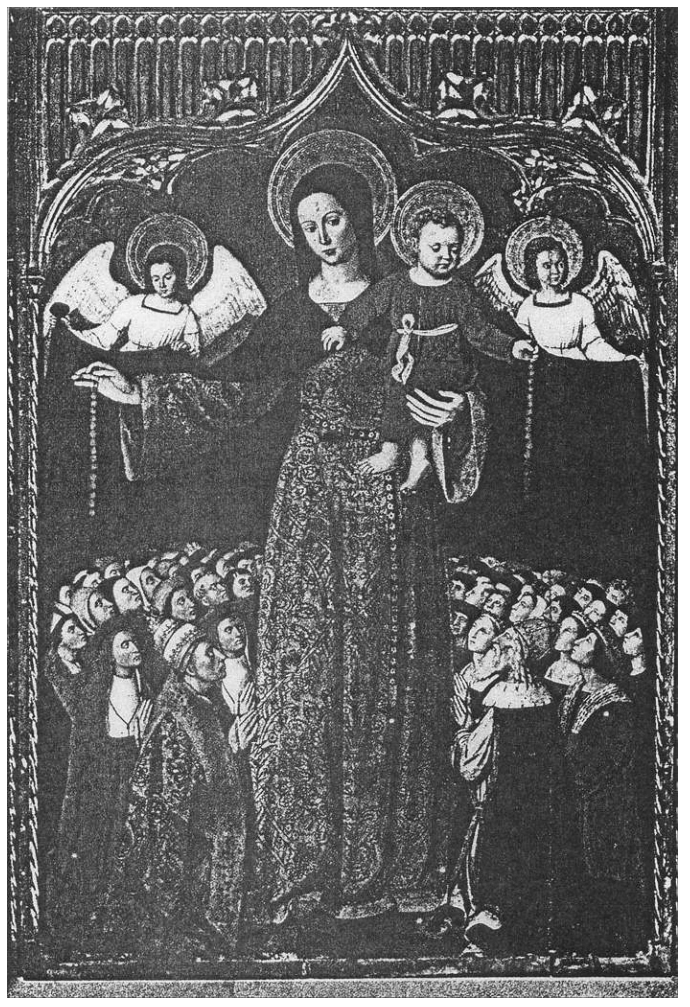

Panneau, église de Biot (Provence).

29 Cette partition des membres d'une société donnée en fonction du genre semble donc constituer un paradigme culturel pour dire simultanément l'interdépendance de deux groupes sociaux et la subordination de l'un par rapport à l'autre. Les moniales au regard des moines, les convers au regard des religieux de chœur, les laïcs au regard des clercs occupent la position sociale, à la fois indispensable et subalterne, du Féminin face au Masculin.

30 L'agencement spatial «sexué » mis en place par l'image inverse celui généralement adopté dans les églises. En effet, l'édifice « réel » était au Moyen Âge socialement divisé en deux dans le sens de la longueur, le côté Sud (celui de l'Épître) étant réservé aux hommes, tandis que le côté Nord (celui de l'Évangile) accueillait les femmes dont la condition forcément pêcheresse, précise Suger, nécessitait une plus grande proximité avec la parole divine ${ }^{37}$. Cette distinctio dans la «maison de Dieu » fut pensée en fonction d'un espace ecclésial en trois dimensions lui-même inscrit dans la croix idéale que forment les quatre points cardinaux, l'autel pointant l'Est. Aussi, dans l'édifice, la droite et la gauche ne prennent-elles sens qu'en relation avec la liturgie du chœur, l'officiant se déplaçant latéralement dans cet espace sacré qui lui est réservé pour énoncer tantôt la parole de Dieu, tantôt celle des Apôtres.

31 Les représentations, elles, prennent leurs distances par rapport au « réel». Tout d'abord parce qu'elles transposent le problème en deux dimensions (même si le manteau de Marie apparaît creusé) mais surtout parce qu'elles offrent une image idéale de l'Église (et non de l'église) qui ne se construit plus à partir de la voix et des gestes du prêtre mais selon le principe du tabernaculum dont la Vierge est la figure. 


\section{La naissance et l'union selon l'esprit dans et par l'Église}

Si Marie instaure indéniablement une barrière entre deux communautés sexuées, son rôle s'avère plus subtil que celui d'une simple frontière étanche: en fait, la Vierge sépare pour mieux réunir. En tant que structure centrale de la distinctio, elle transmute les rapports hommes/femmes en les déplaçant du domaine charnel au domaine spirituel.

En effet, le corps de la Vierge au manteau présente des particularités qui méritent d'être soulignées. Vaste à sa base, il s'amenuise au fur et à mesure que l'on s'élève, évoquant ainsi un cône idéal; la taille de Marie placée (ou plutôt déplacée) très haut, juste sous sa poitrine (cf. Doc. 9), apparait systématiquement bien au-dessus de la tête des sujets qu'elle abrite. Cette silhouette singulière, généralement mise en valeur par un fort contraste chromatique entre la robe et l'intérieur du manteau déployé (Doc. 9 : bleu foncé/blanc), situe ainsi le ventre de Marie, réceptacle du Verbe, en hauteur, audessus du registre des personnages agenouillés. Souvent, les regards de la foule en prière, dirigés vers le haut (surtout lorsqu'il s'agit des dévots laïques - mais les moines ne possèdent-ils pas des "yeux intérieurs" ?), se rejoignent au niveau de la zone des entrailles. Lorsque Marie ne tient pas elle-même écartés les pans de son manteau, ses bras, tendus vers les chrétiens, constituent des «échelles spirituelles" invitant les membres de la société qu'elle abrite à participer au mystère de l'Incarnation (Doc. 9). Le corps de Marie dessine ainsi un véritable chemin allant d'un écart maximal entre hommes et femmes (ou entre clercs et laïcs) au niveau du sol (c'est-à-dire ici-bas) à une quasi-réunion mystique des sujets quelque part sous ses seins. En d'autres termes, plus on s'élève, plus on se rapproche du Fils, plus la distinctio, hiérarchique ou sexuée, se réduit, plus elle perd de son sens. Parfois même, la boucle de la ceinture mariale émet des rayons sacrés afin de manifester précisément cette gestation miraculeuse de la substance divine permettant la réunion mystique de tous les fils de Dieu avec le Fils de Dieu (Doc. 11). 


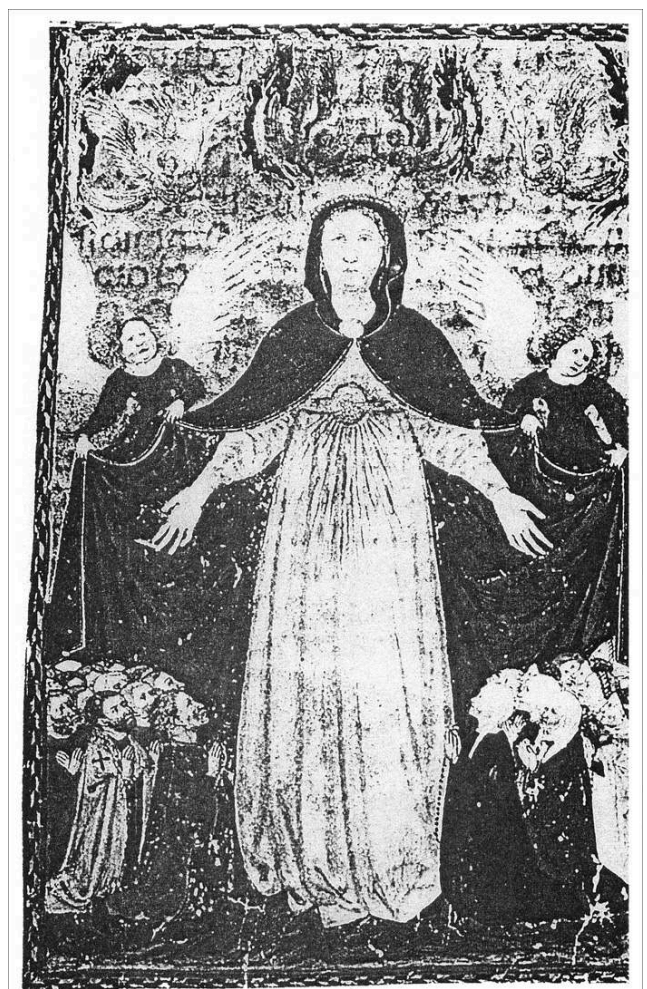

Collection Wildenstein ( $\left.n^{\circ} 78\right)$, Paris, musée Marmottan.

34 Ce processus d'effacement des différences n'est pas sans rappeler les paroles de Paul appliquées au Baptême dans et par l'Évangile :

Oui, vous tous qui avez été baptisés en Christ, vous avez revêtu Christ. Il n'y a plus ni Juif ni Grec; il n'y a plus ni esclave ni homme libre; il n'y a plus l'homme et la femme, car tous, vous n'êtes qu'un en Jésus Christ (Gal. 3, 27-28).

C'est à ce titre que Marie incarne ici à la fois la médiatrice ${ }^{38}$ entre les hommes et Dieu, et l'unificatrice de la société qu'elle abrite, laïque ou religieuse. Parce qu'elle est mère du Rédempteur, elle permet la cohabitation des deux sexes, sur un autre plan. En donnant chair à Dieu, elle fonde la communauté des Chrétiens, en tant que mère du "premier-né d'une multitude de frères » (Rom., VIII, 29). Ainsi, grâce à l'Incarnation dont elle est l'instrument, les hommes et les femmes peuvent à leur tour devenir fils de Dieu (et donc frères du Christ) non pas, comme Jésus, selon les règles trinitaires de la parenté divine, mais selon les mécanismes théologico-sociaux de la parenté spirituelle $^{39}$. La dimension foncièrement ecclésiale de la Vierge, instituant et réunissant la fraternité des chrétiens, s'affirme alors.

Le thème de la Vierge-Église, maintes fois étudié ${ }^{40}$, parcourt 1'ecclésiologie de façon récurrente depuis les Pères. Mon propos n'est donc pas ici d'en retracer l'histoire, mais plutôt d'en chercher les traces dans les textes cisterciens qui pourraient entrer en résonnance avec les images de la Vierge au manteau.

L'abbé Isaac de l'Étoile (1110/20-1169), dans ses sermons pour l'Assomption, développe à plusieurs reprises cette idée. Le sermon $51^{41}$, très dense, insiste sur la réciprocité des fonctions entre Marie et l'Église en s'appuyant sur la métaphore du corps pour 
manifester de façon organique l'indissociabilité entre le Fils et l'Assemblée des chrétiens :

Il n'y a qu'un unique et total et seul Christ, tête et corps. Et cet unique - du Dieu unique dans le ciel et d'une Mère unique sur la terre - est à la fois multitude de fils et unique Fils. Et comme la tête et les membres sont un seul Fils et plusieurs fils, Marie et l'Église sont une seule mère et plusieurs, une seule vierge et plusieurs. L'une et l'autre est mère; l'une et l'autre vierge. L'une et l'autre, sans trouble charnel, conçoit du même esprit; l'une et l'autre, sans péché, donne une progéniture à Dieu Père. L'une, hors de tout péché, a mis au monde la tête de ce corps ; l'autre, dans la rémission de tous les péchés, a donné le jour au corps de cette tête. L'une et l'autre est Mère du Christ, mais aucune des deux ne l'enfante tout entier sans l'autre. Aussi, c'est à bon droit que dans les Écritures divinement inspirées, ce qui est dit universellement de l'Église, Vierge-Mère, est compris singulièrement de Marie, Vierge-Mère; et ce qui est dit spécialement de Marie, Vierge-Mère, est compris généralement de l'Église, Vierge-Mère ${ }^{42}$.

Marie est donc mère du Christ tout comme l'Église est mère de tous les chrétiens qui forment collectivement le corps mystique du Christ. Cette notion de maternité de la Vierge-Église donnant naissance spirituellement à la multitude des fils de Dieu est exprimée dans l'image par le statut ambigu du manteau qui évoque à la fois le bâtiment ecclésial regroupant l'assemblée des chrétiens et un "ventre élargi» acceptant d'accueillir, en bas et à sa périphérie, les enfants spirituels du Père, tandis que l'uterus central et haut perché demeure réservé au Fils par excellence, cœur du tabernacle ${ }^{43}$.

L'incorporation des chrétiens (et en particulier des Moines Blancs) à l'intérieur des limites «textiles» de la Vierge est justifiée, dans les textes cisterciens, par le désir de conformatio qui habite les fils spirituels de Dieu. Le Père a envoyé son fils parmi les hommes afin que ceux-ci possèdent un «modèle visible » de lui-même leur permettant de tendre vers la Ressemblance.

C'est un autre auteur cistercien, Guerric d'Igny ( $† 1157)$ qui a le mieux exprimé ce phénomène d'adoption par Dieu des chrétiens en tant que créatures se devant de réaliser en eux l'Image du Père révélée par le Fils.

Dans son premier sermon sur l'Assomption, l'abbé déclare : « Cette unique Vierge Mère, qui se glorifie d'avoir mis au monde le Fils unique du Père, étreint avec amour ce même Fils unique en tous ses membres; et elle ne rougit pas d'être appelée mère de tous ceux dans lesquels elle reconnaît son Christ déjà formé ou en formation $»^{44}$. De même, dans son deuxième sermon pour la Nativité, Guerric loue Marie qu'il compare à Sarah, la femme stérile qui enfanta finalement, sur intervention divine, tout un " peuple élu»: " Ô Mère vierge, vierge féconde... Il est en effet le fils du Très-Haut pour qui le Père les a adoptés afin qu'ils soient tous conformes à son image, et qu'il soit le premier-né d'une multitude de frères. Élargis donc l'espace de ta tente, de l'Orient au Couchant et d'une mer à l'autre ; car tu t'étendras à droite et à gauche, et ta race possédera les Nations en héritage $\aleph^{45}$. Guerric glose ici Isaïe $(54,1-3)$ qui présente Jérusalem comme l'ensemble des descendants de Sarah : « car les voici en foule, les fils de la désolée, plus nombreux que les fils de l'épousée, dit le Seigneur. Élargis l'espace de ta tente; les toiles de tes demeures, qu'on les distende! Ne ménage rien! allonge tes cordages et tes piquets, faisles tenir, car à droite et à gauche tu vas déborder $»^{46}$. La virginité de Marie prend le relais de la stérilité de Sarah, l'un et l'autre phénomènes mettant en valeur a contrario la fécondité du spirituel et la sacralité d'une descendance conçue hors du commerce charnel. Le réemploi, par l'abbé cistercien, de l'image de la tente (métaphore vétérotestamentaire), s'avère particulièrement bien adapté à cette Vierge-Église-peuple 
de Dieu oscillant entre corps et édifice. La tente, «maison-textile », comme le manteau de Marie, et comme le corps de la femme, présente une certaine élasticité qui permet de loger, ou tout au moins d'envelopper, une myriade de fils, « à droite et à gauche ».

Doc. 12. Jean Bellegambe, La Vierge des Cisterciens (début XVIe siècle)

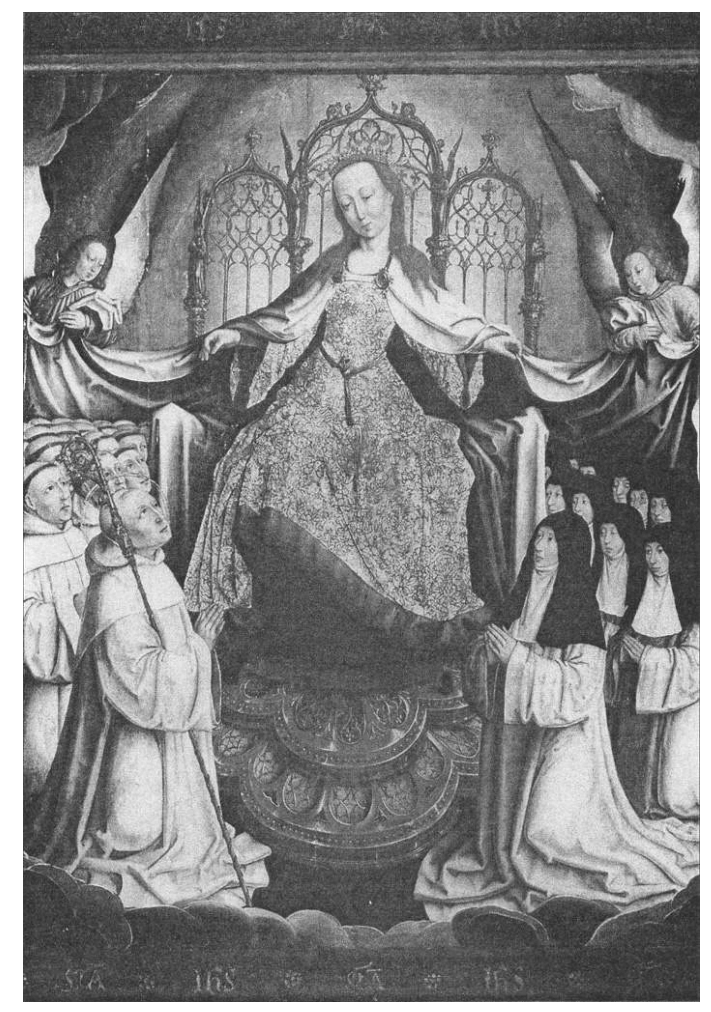

Retable, Douai, musée de la Chartreuse.

La fraternité ecclésiale, générée par le corps de Marie et unifiée par son extension textile, le manteau, présente parfois une connotation sacramentelle plus marquée. C'est le cas dans le panneau cistercien attribué à Jean Bellegambe, peint au début du $\mathrm{XVI}^{\mathrm{e}}$ siècle, et conservé de nos jours à Douai, au musée de la Chartreuse ${ }^{47}$ (Doc. 12). Dans cette image, Marie n'apparaît plus debout mais assise sur un trône, en grande partie dissimulée par son large manteau bleu maintenu ouvert par deux anges. L'étrange cathedra qui la supporte correspond en fait à une structure composite dont la base reprend expressément le pied orfévré des calices tandis que le dossier évoque 1 'armature travaillée des verrières gothiques. Les articulations logiques entre les différents éléments du siège sont subtilement éludées par des zones d'ombre très dense, d'un noir profond, conférant du même coup un fort relief au corps mordoré de la Vierge émergeant de l'obscurité comme un joyau. C'est la silhouette de Marie qui donne sa cohérence à cet «édifice eucharistique » dont elle incarne à la fois le cœur et le principe. Le manteau recouvre les accoudoirs du "siège ", isolant ainsi la Vierge sur son piédestal, et la rendant indissociable de son trône.

43 La famille cistercienne (masculine/féminine) agenouillée en contrebas, est abritée comme il se doit par le manteau marial largement écarté ; néanmoins, elle n'est pas intégrée au trône eucharistique, réservé à la Mère de Dieu. Une seconde enveloppe, ronde, surtout perceptible aux angles du panneau, intervient alors dans l'image afin de mieux englober l'ensemble de la scène, de circonscrire en un même lieu la Vierge et 
l'ordre cistercien. Les nuées floconneuses irradiées par une lumière divine chatoyante constituent cette seconde « enceinte ».

Tout un système d'emboîtement est donc à l'œuvre dans cette représentation, allant du lieu paternel (la couronne de nuées), à l'évocation eucharistique du Fils (la base du trône), en passant par la Vierge, pilier de l'Incarnation, centre d'un édifice ecclésial sacramentel qui enserre l'ordre cistercien. Dans cette atmosphère trinitaire, la lumière jaune, située juste derrière Marie et traversant sans la briser la "verrière virginale ", ne peut qu'induire la présence de l'Esprit. La couronne de la «Reine des Cieux » finit par se confondre avec le décor flamboyant des baies gothiques dont le sommet est marqué de trois cercles entrelacés.

La base du trône, figurée comme un pied de calice, induit donc que le corps du Christ porté par Marie est un corps sacramentel destiné à fondre ceux qui l'avalent en un seul et même corps mystique. Dans cette perspective, les moniales et les moines cisterciens se muent non seulement en filles et fils de Dieu mais également en membres du corps christique. L'ordre élabore ainsi une image unitaire de lui-même calquée sur le modèle paulinien d'une Église christique corporéisée.

Cette réunion mystique des membres de l'ordre avec un Dieu trinitaire via la Vierge rompt d'une certaine façon avec les Vierges au manteau jusqu'ici étudiées, qui apparaissaient bien ancrées sur un sol terrestre (la plupart du temps herbu) accueillant la société des hommes (Doc. 9,11) ou bien celle des moines (Doc. 8). Les pans écartés du manteau marial, descendant jusqu'à terre, délimitaient alors le monde sublunaire, audessus duquel s'agitaient les anges, occupés à retenir de leurs mains graciles la voûte textile de ce monde terrestre. Dans le panneau de Douai, toute la scène se situe visiblement au ciel, comme dans la vision rapportée par Césaire de Heisterbach. La participation mystique des religieux au corps divin apparaît alors comme la récompense ultime de leur action ici-bas.

Guerric d'lgny, dans son premier sermon pour l'Assomption, insiste sur cette continuité de l'action mariale protégeant dès ici-bas l'ordre cistercien et le glorifiant dans les cieux: "Maintenant, en effet, nous habitons à l'abri de la Mère du Très-Haut, nous demeurons sous sa protection comme sous l'ombre de ses ailes; plus tard, nous serons comme réchauffés dans son sein (in sinu) en partageant sa gloire. Alors tous diront d'une seule voix, joyeux et félicitant leur mère "Nous tous qui sommes dans la joie, notre demeure est en toi, sainte Mère de Dieu" $\aleph^{48}$. Comme dans le récit de Césaire de Heisterbach, la Vierge au Manteau constitue donc, au ciel, un lieu paradisiaque particulièrement privilégié, finalement proche du Sein d'Abraham qui réunit, lui aussi dans un " tissu corporéisé ", l'ensemble des Élus ${ }^{49}$. Mais alors que le sein d'Abraham se présente sous la forme d'un berceau concave, signe d'une incorporation glorieuse au Père, le manteau de la Vierge dessine une tente-tabernacle convexe, signe de la participation mystique au corps ecclésial du Christ. La première enveloppe, ouverte vers le haut, gomme les facteurs de distinctio (âge, sexe, statut social) au profit de l'uniformité paradisiaque du peuple des Élus; la seconde enveloppe rend manifeste la distinctio afin de mieux affirmer la puissance de la parenté spirituelle pouvant unir, sur terre, les différences (sociales et/ou sexuées) en un même corps mystique fraternel. Guerric d'lgny, en tant qu'auteur cistercien admirateur de la Vierge, affirme d'ailleurs sa préférence pour le sein de Marie, réceptacle du Verbe et siège de la Rédemption menant à la victoire : « Mais ne crois surtout pas qu'il y ait plus de bonheur et de gloire à habiter dans le sein d'Abraham que dans le sein de Marie alors que le Roi de Gloire a 
placé en elle son trône $"^{50}$. À l'aune de ces paroles, le trône composite et eucharistique du panneau de Douai se charge de toute sa sémantique, théologique et téléologique, dans la mesure où l'uterus s'affirme comme la condition sine qua non de la Résurrection.

\section{Vierge-Mère et Père fondateur. histoire d'une cohabitation impossible}

Les Cisterciens ne sont pas les seuls moines à s'être agrégés sous le pallium de Marie. Les Chartreux, dont la dévotion mariale n'a rien à envier à celle des Moines Blancs ${ }^{51}$, utilisèrent également l'image de la Vierge au manteau, bien que plus tardivement (pas avant la fin $\mathrm{du} \mathrm{XV}^{\mathrm{e}}$ siècle) et beaucoup moins fréquemment que leurs devanciers. Pour la période médiévale, la seule représentation qui nous soit parvenue est un panneau (peint sur bois puis transposé sur toile) conservé au Musée colonais Wallraf-Richartz ${ }^{52}$ (Doc. 13). Il ornait jadis la Chartreuse Sainte-Barbe de Cologne, « désert urbain » fondé en 1334 par l'archevêque Walram ( $† 1349)$ siégeant alors en cette citéf ${ }^{53}$. Le monastère, ancré dans la ville natale de Bruno, devint aux XVe et XVI ${ }^{\mathrm{e}}$ siècles un ardent foyer de culture et de spiritualité, nombre de profès étant issus des cercles humanistes de l'université de Cologne. On ignore où se trouvait précisément le panneau, peut-être sur l'un des murs du petit cloître dont le trajet était ponctué de trois autels dédiés respectivement aux Armes de la Passion, aux Saints Anges et à la Vierge Marie ${ }^{54}$.

Doc. 13. Maître allemand inconnu, La Vierge au manteau des Chartreux (fin XVe siècle)

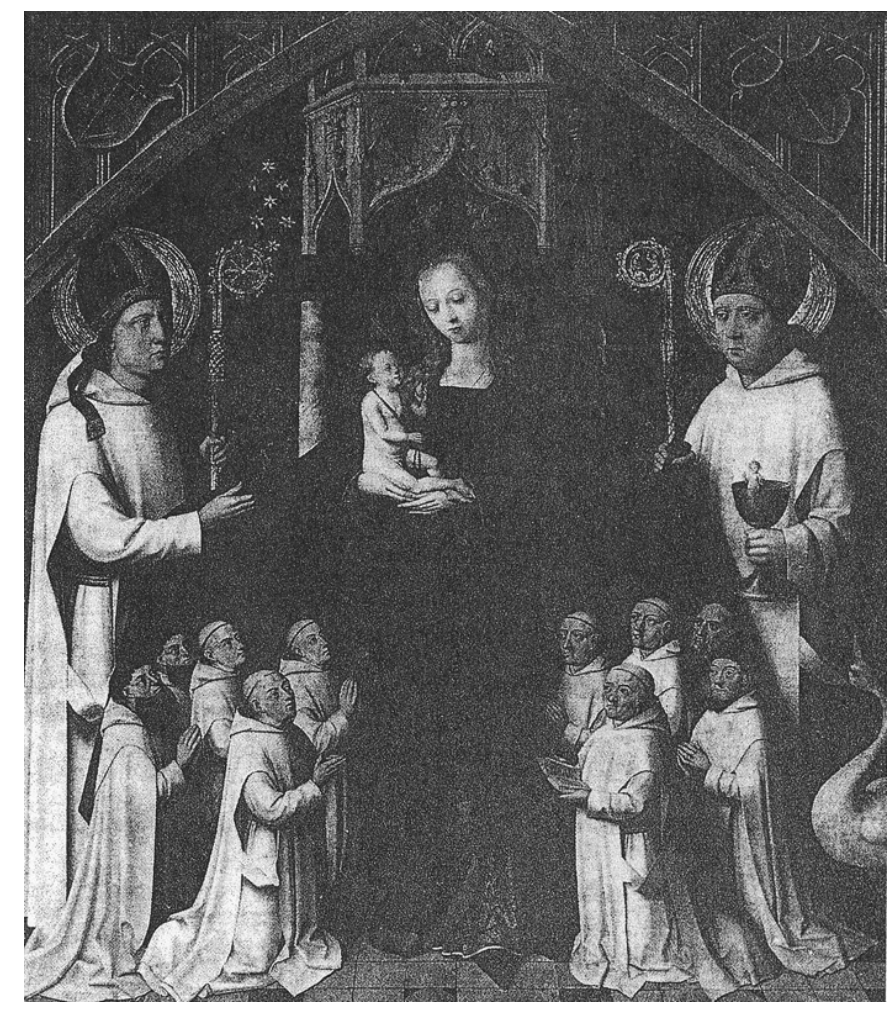

Retable, Cologne, musée Wallraf-Richartz.

Le tableau cartusien, daté des années 1475-1480, fut offert à la Chartreuse par Johann Rinck et son fils Peter, médecins à Cologne. Désireux d'unir leur âme à la societas 
monachorum, les deux donateurs, dont les figures ont été découpées pour faire l'objet de petits panneaux indépendants, étaient à l'origine représentés en prière, agenouillés à même le sol, de part et d'autre de la Vierge. Leurs armoiries familiales, posées devant eux, permettent de les identifier.

Cette Vierge au manteau diffère de la plupart des Vierges cisterciennes sur plusieurs points : tout d'abord, elle ne constitue pas, comme d'ordinaire, l'axe fondamental de la distinctio mais plutôt celui de la similitudo. En effet, l'immense effigie de Marie ne distingue pas ici les religieux des religieuses, ni même les moines profès des frères convers ${ }^{55}$. Au contraire, son corps instaure un rapport spéculaire entre les cinq Chartreux agenouillés à sa droite et les cinq Chartreux agenouillés à sa gauche. L'organisation des deux groupes, tant dans leur disposition spatiale $(2 \nmid 1 \dagger 2)$ que dans leur composition ( 3 moines $\uparrow 2$ convers) s'avère strictement similaire ${ }^{56}$.

51 Cette symétrie sociale de l'ordo de part et d'autre du corps marial ne répond pourtant pas ici au hiératisme axial de la Vierge. En effet, la « silhouette ecclésiale », frontale et bras écartés, si souvent rencontrée dans les images déjà étudiées (cf. Doc. 2, 3, 7, 8, 9, 11) cède ici la place à un " déséquilibre corporel » provoqué par l'Enfant Jésus. Celui-ci, posé sur le bras droit de la Vierge, oblige sa mère à avancer le pied gauche. Quant au visage de Marie, il échappe lui aussi au hiératisme en s'inclinant vers le Fils.

Aussi, dans cette image, la figuration explicite du " fruit des entrailles ", en décentrant l'armature ecclésiale, semble modifier les rapports entre le corps de la Vierge et la micro-société idéale lovée sous son manteau. Marie étant tout absorbée par son Fils divin, les liens mystiques qu'elle entretient avec les fils spirituels de Dieu se distendent, passent au second plan. La parenté spirituelle s'estompant, les moines-ermites ont tendance à redevenir de simples dévots agenouillés au pied d'une immense statue de la Vierge à l'Enfant ${ }^{57}$.

53 La Vierge au manteau des Chartreux n'assume donc plus entièrement son rôle de Mère spirituelle conférant son unité fraternelle à un corps social donné. Néanmoins, d'autres intervenants viennent ici pallier cette "défaillance». Marie, bien que constituant toujours le pivot de la représentation et la charnière du miroir, n'est plus le seul et unique " grand personnage » à incarner 1'Ecclesia. Tout se passe comme si l'Édifice avait désormais trois pôles: certes, un pilier central, dont la sacralité est soulignée par le dais gothique, mais aussi deux colonnes latérales, figurées à la même échelle que la Vierge, et sanctifiées par des auréoles dorées. Ces deux figures, situées à l'extérieur du manteau, en maintiennent néanmoins ouverts les larges pans: d'une certaine façon, elles évincent les anges, brouillant du même coup la frontière entre monde céleste et monde sublunaire.

Les deux évêques latéraux non seulement n'échappent pas au principe général d'organisation spéculaire mais ils participent pleinement à son instauration. D'abord par leur nom : à gauche se trouve Hugues de Grenoble (1053-1132), qui offrit en 1084 à Bruno et à ses six premiers compagnons le désert de Chartreuse; à droite se tient Hugues de Lincoln (1140-1200), entré à la Grande Chartreuse en 1166 (dont il devint procurateur), élu prieur de la chartreuse anglaise de Witham en 1179, et nommé évêque de Lincoln en 1188, sur intervention d'Henri II. La crosse du premier est surmontée des sept étoiles qui évoquent le rêve de l'évêque annonçant l'implantation de la communauté princeps dans son diocèse ${ }^{58}$. Le second est flanqué du cygne sauvage qu'il sut apprivoiser; il porte également le calice d'où émerge l'enfant Jésus, son second attribut $^{59}$. Les deux saints, vêtus en Chartreux comme les moines agenouillés (alors 
qu'Hugues de Grenoble ne prit jamais l'habit) contribuent donc à maintenir l'armature ecclésiale conférant au groupe monastique sa cohérence spéculaire, sa forma en miroir. La question qui s'impose alors est celle de l'absence de Bruno. En effet, participer à créer l'unité de l'ordo semblerait relever davantage, sur un plan anthropologique, du Père spirituel, « modèle » de sa propre familia religieuse, que de saints associés à l'ordre (ou issus de lui).

On peut toujours, dans un premier temps, invoquer les "contingences" propres à l'ordre cartusien. Bruno (c. 1030-1101), bien qu'initiateur d'un style de vie original, miérémitique, mi-cénobitique, n'a jamais accédé véritablement, durant la période médiévale, au statut de Père fondateur d'un ordre religieux ${ }^{60}$. La fondation de la Grande Chartreuse (qui deviendra la maison mère du réseau cartusien) est relatée non pas dans la vita de saint Bruno, inexistante en tant que telle au Moyen Âge ${ }^{61}$, mais dans celle de l'évêque de Grenoble, Hugues, qui accorda à la communauté originelle le lieu sauvage et solitaire de sa première expérience ${ }^{62}$. C'est donc un récit à la gloire de l'évêque qui a diffusé subséquemment l'histoire de l'exorde cartusien, une histoire dans laquelle le « premier des chartreux » ne tient pas le premier rôle.

D'autre part, Bruno n'a pas laissé de règle, ni d'écrits législatifs, permettant de prolonger après sa mort l'exemple qu'il incarnait de son vivant. C'est Guigues $\mathrm{I}^{\mathrm{er}}$, cinquième prieur de la Grande Chartreuse, qui rédigea en 1127 les coutumes de l'ordre ${ }^{63}$. L'identification entre le Père et le texte de la forma vitae (si prégnante dans le cas de saint Benoît) ne s'est donc pas produite dans l'ordre cartusien. Enfin, le fait que Bruno, originaire de Cologne $e^{64}$, ne se soit pas fixé au locus originel (la Grande Chartreuse) mais ait poursuivi son expérience spirituelle en Calabre entrava la cristallisation d'un "mythe fondateur" autour de sa personne, mythe liant toujours fortement le paterfamilias à une "topographie des origines $"^{65}$. L'approbation définitive de l'ordre par le Saint-Siège (le 2 septembre 1171) n'intervint qu'après la mort de Bruno (1101), qui ne sera béatifié qu'au XVI ${ }^{\mathrm{e}}$ siècle, l'année où l'on réinventa son corps-relique (1514) tombé dans l'oubli depuis plus de quatre siècles. Il faudra attendre 1623 pour que le moine-ermite accède à la canonisation.

Néanmoins, l'évincement de Bruno ne doit pas être jugé uniquement à l'aune de l'histoire cartusienne. Il invite au contraire à reconsidérer les images cisterciennes, et à s'interroger sur le statut du fondateur dans cette autre famille religieuse.

Il est en effet troublant que le thème iconographique de la Vierge au manteau ait été élaboré par un ordre monastique rencontrant lui aussi des problèmes de positionnement quant à la figure de son fondateur. L'ordre cistercien, fondé historiquement par Robert de Molesmes, ne reconnut jamais véritablement en ce moine pionnier son Père spirituel. À l'instar de Bruno (mais pour d'autres raisons), Robert ne se fixa pas au lieu princeps de l'expérience, Molesmes, mais le quitta bientôt pour fonder Cîteaux, avant de retourner, contraint et forcé par le Saint-Siège, au lieu d'origine. S'est alors instauré un brouillage de la topographie initiale. D'autre part, comme Bruno, Robert ne laissa à sa mort aucun texte législatif consignant le mode de vie qu'il avait inauguré. C'est probablement Étienne Harding, abbé de Cîteaux de 1109 à 1133, qui rédigea la Carta Caritatis ${ }^{66}$. Robert, Père fondateur aux contours estompés, fut donc aisément supplanté par le charismatique saint Bernard ${ }^{67}$ (élu abbé de Clairvaux en 1115) qui n'incarna lui-même qu'une sorte de "père second $»^{68}$ : Benoît (et sa règle) demeura en effet la référence originelle primordiale des Cisterciens, à laquelle saint 
Bernard est censé renvoyer directement, comme pour mieux nier l'expérience clunisienne.

Sous le manteau des Vierges cisterciennes non sigillaires (les sceaux évinçant, comme nous l'avons vu précédemment, toute représentation de l'autorité abbatiale au profit du pouvoir partagé), se trouve néanmoins un abbé, agenouillé en tête de son « troupeau monacal sexué » (cf. Doc. 8 et 12); une moniale lui fait pendant du côté féminin, sans pour autant arborer la crosse ${ }^{69}$. Bien qu'il soit objectivement impossible d'identifier l'abbé qui figure sur le frontispice des Privilèges (Robert de Molesmes? Bernard? un abbé générique ? les trois à la fois ?), les circonstances de la commande permettent de le faire pour le panneau de Douai ${ }^{70}$. Saint Bernard, dont on aperçoit l'auréole translucide, correspond bien à l'abbé en prière aux pieds de la Vierge. Le supérieur de l'abbaye de Clairvaux s'impose ici comme le chef de l'ordo qui se presse derrière lui. La religieuse lui faisant face correspond, elle, à Jeanne de Boubais, abbesse du monastère de Flines, et Supérieure, à ce titre, d'lsabelle de Maléfiance, l'aristocratique moniale qui commanda à Bellegambe le tableau.

Saint Bernard, père fondateur au positionnement ambigu, se distingue du reste de l'ordo en s'affirmant comme le berger sanctifié de son troupeau, et sans doute comme le premier des admirateurs de la Vierge ${ }^{71}$. Mais son statut paternel, peu connoté, fait qu'il se range somme toute parmi les siens. La relation de parenté spirituelle qu'il entretient avec ses fils, peu marquée, ne peut entrer en concurrence avec la maternité spirituelle de la Vierge, triomphante, englobante, incorporante, et qui métamorphose systématiquement les individus blottis sous son manteau en " enfants » minuscules, en fils de Dieu, même s'ils furent ici-bas des abbés d'envergure (et quasiment des "Pères ») pour leurs coreligionnaires.

61 Force est donc de constater que ce sont les ordres monastiques dont la figure du Père fondateur est peu affirmée qui ont élaboré et/ou utilisé les représentations de la Vierge au manteau. Il semble que la puissante «maternité ecclésiale» de Marie ne puisse cohabiter avec l'idée d'un Père spirituel fort, engendrant lui-même sa famille religieuse, ou tout au moins lui imprimant sa forma. D’ailleurs, ni les Bénédictins, ni les Franciscains, pour qui le fondateur joue un rôle central de modèle fédérateur, n'ont éprouvé le besoin de s'abriter sous le manteau de Marie. La Madonna dei Francescani,peinte par Duccio vers 1300 (souvent classée parmi les Vierges de Miséricorde pour alimenter le mythe selon lequel tous les ordres ont utilisé ce thème iconographique) n'abrite que trois Frères Mineurs, tous situés du même côté, et qui semblent de surcroît figurer un seul et même personnage dans trois positions successives de prière. Elle n'entre donc pas à mon sens dans notre corpus.

Pourtant, les Vitae de François offraient une substance textuelle qui aurait pu être propice au développement d'une image singulière : non pas celle de la Vierge abritant les Frères Mineurs assemblés, mais celle du Poverello regroupant lui-même ses fils sous ses ailes. En effet, aux paragraphes 23-24 (chapitre XVI) de la Vita Secunda (1247), Thomas de Celano rapporte un rêve qui envahit le fondateur en personne ${ }^{72}$ :

Une nuit, durant son sommeil, il eut une vision. Une poule petite et noire, pas plus grosse qu'une colombe, aux pattes couvertes de plumes, avait d'innombrables poussins qui piaillaient sans cesse en tourbillonnant pour lui demander abri, mais elle ne parvenait pas à les réunir sous ses ailes. Au réveil, l'homme de Dieu reprit en son cœur le cours de ses méditations et, interprétant lui-même sa vision. "Cette poule, dit-il, c'est moi avec ma petite taille et mon teint noir ; elle doit agir avec la simplicité de la colombe, c'est-à-dire avec innocence, et elle gagnera le ciel d'autant 
plus facilement qu'elle paraîtra moins dans le monde. Les poussins sont mes frères nombreux et vertueux que mes pauvres forces ne suffisent pas à mettre à l'abri des calomnies et des persécutions"73.

63 Ce rêve apparaît comme un " équivalent inversé » des images déjà étudiées (même si temporellement, il leur est antérieur) : il affirme la petite taille et la modestie ${ }^{74}$ de la poule, là où les représentations insistent sur l'imposante stature de Marie, démesurément grande par rapport à la societas monachorum qu'elle abrite ; les petites plumes noires et les trop courtes ailes de l'oiseau s'opposent de facon flagrante aux riches et abondants tissus, colorés ou mordorés, dont est revêtue la Vierge, depuis sa robe jusqu'à son pallium; quant à la progéniture cherchant refuge à l'ombre de la Mère, autant la société des moines s'avère statique et ordonnée, autant les poussins, incapables de faire corps, évoquent le désordre, la panique et la dispersion.

Par ce rêve prophétique ${ }^{75}$, François laisse émerger sa crainte de voir poindre à l'intérieur de la fraternitas des dissensions ${ }^{76}$; il redoute également de voir apparaître des attaques à l'encontre de ses fils, provenant de l'extérieur. Le rôle qui lui incombe, en tant que fondateur, est alors double: unir et protéger, c'est-à-dire incarner à l'intérieur le pôle fédérateur de 1'ordo, son cœur centripète, et construire simultanément tout autour de la fraternitas une membrane protectrice: en d'autres termes, le Poverello se doit d'instaurer à la fois le centre et la périphérie de sa familia.

Néanmoins, cette fonction d'autorité structurante, affermissant la fraternité de l'intérieur tout en affirmant sa place respectable aux yeux de l'extérieur, semble dépasser François, ou tout au moins lui répugner. Le modèle scripturaire qui sous-tend ce récit est effectivement celui d'un échec, formulé par Jésus au Temple sous forme de reproche (Mat. 23, 37) : "Jérusalem, Jérusalem, toi qui tues les prophètes et lapides ceux qui te sont envoyés, que de fois j'ai voulu rassembler tes enfants (congregare filios tuos) comme une poule (gallina) rassemble ses poussins (pullos suos) sous ses ailes (sub alas), et vous n'avez pas voulu!». Les liens entre ce passage évangélique et la vita de François amènent à relativiser le caractère exclusivement maternel de la poule, ou tout au moins à le replacer dans un mécanisme spirituel plus vaste. Si le Poverello s'imagine en gallina, c'est autant, dans un premier temps, pour s'inscrire dans les pas du Christ, que pour affirmer la "féminisation"spécifique à son propre pouvoir ${ }^{77}$. La double fonction qu'il se devrait de remplir, constituer le modèle absolu de ses frères tout en les enveloppant, en les circonscrivant en un seul et même corps, correspond particulièrement bien à la figure ambivalente du Christ, à la fois Père et Mère, si souvent reprise en milieu monastique pour qualifier et justifier le rôle de l'Abbé ${ }^{78}$. Être poule, c'est donc aussi (même si nous peinons à le concevoir aujourd'hui), être le Christ. Mais le rêve du Poverello est en quelque sorte un aveu explicite d'impuissance ${ }^{79}$ (ou du moins l'expression onirique d'un refus du pouvoir autocratique) qui le distingue fondamentalement, dans sa réponse, du Fils incarné. Là où Jésus menace de transformer la maison de Jérusalem en un « désert stérile », François, Père spirituel se refusant à toute sanction-vengeance contre ses fils, transfère son pouvoir vers une grande figure féminine, la « Sainte Église Romaine » qui seule parviendra, en son vaste corps, à juguler les dangers internes et externes qui guettent l'Ordo en formation, quitte à employer elle-même la force.

J'irai donc et je les confierai à la Sainte Église Romaine. Elle a puissance pour châtier nos ennemis et garantir ainsi aux enfants de Dieu la pleine liberté pour permettre à un plus grand nombre d'être sauvés. Les fils, pleins de reconnaissance pour les bienfaits de leur Mère, s'attacheront de tout leur cœur à suivre toujours ses traces 
sacrées. Aucune attaque, d'autre part, ne viendra bouleverser l'Ordre sous sa protection et le fils de Bélial ne pourra pas traverser impunément la vigne du Seigneur. [...] Elle conservera sauf parmi nous le lien de la paix et de la charité, infligera aux dissidents des peines très sévères ${ }^{80}$.

La seule issue que conçoit François pour sauver son ordre, troublé à l'intérieur, attaqué à l'extérieur, est celle d'une incorporation de celui-ci dans l'Ecclesia. Pour reprendre les termes de Jacques Dalarun, «cette maternité allégorique est le moyen imaginé par le fondateur pour résoudre les énormes difficultés nées de ce passage même de la fraternité à l'institution et qui se résument en deux interrogations lancinantes: comment gouverner l'ordre sans dominer? Comment le mettre en si étroite conformité à l'Église qu'il puisse sembler, en elle, venir se confondre? $»^{81}$. Ainsi, le rêve de François, et son interprétation par lui-même, confirme sans ambiguité le mécanisme déjà décelé chez les Cisterciens et les Chartreux: la figure de la Mater Ecclesia protectrice, garante de l'unité de l'ordre, émerge lorsque celle du fondateur s'estompe, ou bien quand celui-ci refuse de jouer le rôle de l'Abbé-Tout-Puissant ${ }^{82}$.

\section{La victoire des Dominicains sur les Cisterciens ou l'apologie de la clôture intérieure}

Qu'en est-il de l'autre ordre mendiant, celui des Frères Prêcheurs, qui développa une « historiographie hagiographique » d'emblée très collective, non exclusivement centrée sur la personne de son fondateur ${ }^{83}$ ? Son utilisation de la Vierge au manteau, peu fréquente durant la période médiévale, ne présente pas d'originalité particulière. L'image la plus remarquée, de par son auteur, Fra Angelico, se trouve au folio $156^{\mathrm{v}} \mathrm{du}$ luxueux missel 558 conservé au Musée San Marco de Florence ${ }^{84}$ (Doc. 14). Marie est insérée dans une initiale $S$ ouvrant précisément l'introït de la messe pour la fête de la Vierge: Salve sancta parens enixa puerpera regem qui caelum terramque regit in saecula saeculorum. La Mater Dei, dont le fruit des entrailles n'est pas figuré, mantient elle-même ouvert les pans de son pallium révélant ainsi cinq Frères Prêcheurs en prière à ses pieds. Son corps, telle une colonne verticale, crée le lien entre l'ici-bas (l'espace d'action des religieux) et l'au-delà (l'espace radieux de la promesse), la séparation entre les deux registres (caelum terramque) étant accentuée par les méandres de la lettre que forment deux énormes poissons gloutons inversés. 
Doc. 14. Fra Angelico. Initiale S (v. 1430)

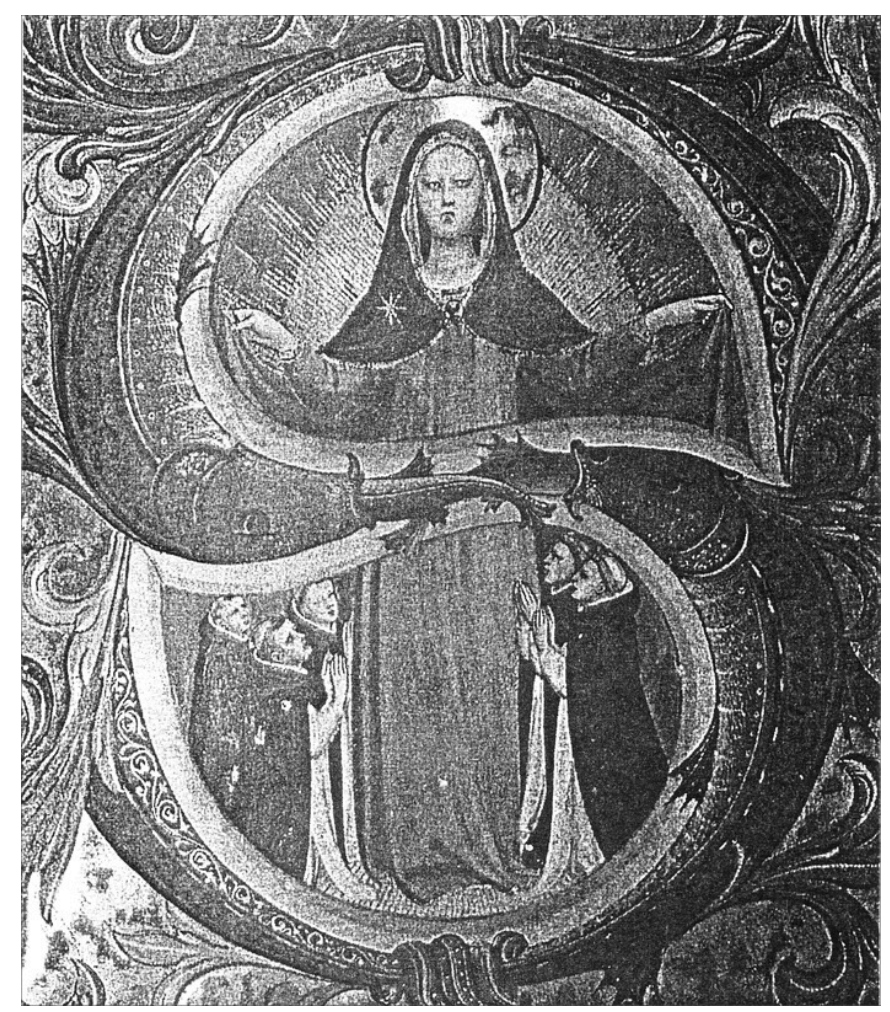

Florence, musée San Marco, missel 558, fol. 156v

69 Il faut en fait se tourner vers les textes dominicains pour découvrir un riche dossier construit comme un « reflet antagoniste» du dossier cistercien. En effet, la dévotion appuyée que les Dominicains vouèrent à la Vierge Marie ${ }^{85}$ les plaça très vite en concurrence directe avec les Cisterciens (qu'ils supplantèrent également sur le terrain de la lutte contre l'Hérésie, grâce, notamment, à une " parole nouvelle »). Le fait s'avère particulièrement sensible dans les légendes hagiographiques, à commencer par le Bonum Universale de Apibus de Thomas de Cantimpré † c. 1270-1272), rédigé entre 1256 et $1263^{86}$. L'auteur de ce traité, un ex-chanoine régulier passé à l'Ordre des Frères Prêcheurs, dédie son œuvre à Humbert de Romans, alors Maître Général de l'Ordre (1254-1263). Très laudatif pour l'Ordre des Dominicains, cet ouvrage s'avère a contrario polémique et impitoyable envers les concurrents des Frères, ainsi qu'à l'encontre des « ennemis des Chrétiens », en particulier les Juifs. Un principe de comparaison entre les religieux et les abeilles (et donc entre le cloître et la ruche) régit la structure générale du traité, composé d'anecdotes édifiantes.

$70 \mathrm{Au}$ paragraphe 17 du livre II, l'auteur rapporte deux visions visant à affirmer que la Vierge est la patronne exclusive des Frères Prêcheurs. Dans le premier de ces récits, Marie déconcerte un Moine Blanc en le dépossédant de son statut privilégié :

Sur ce sujet (la défense de l'ordre dominicain), voici une vision admirable reçue par un moine cistercien, moine de vie si sainte qu'il serait honteux et impie de ne pas le croire. Ravi en esprit, il vit la patronne de l'ordre cistercien, la très douce mère du Christ Jésus. La bienheureuse Vierge lui déclara: "Je recommande à ta charité mes frères et mes fils pour que ton amour et ta prière pour eux soient plus sincères et plus intenses". Et comme le moine approuvait en pensant qu'il s'agissait des frères de son ordre, la Vierge continua: "J'ai d'autres frères que je prends sous mon patronage pour les protéger et les garder". À ces mots, elle ouvrit son manteau pour 
montrer les frères de l'ordre des prêcheurs logés dessous et elle ajouta : "Voici ceux qui s'appliquent au ministère spirituel pour que le sang de mon Fils n'ait pas été répandu en vain" ${ }^{\prime 7}$. d'une recluse, installée quelque part en Lombardie :

Il y avait en Lombardie une recluse dont la dévotion pour Notre Dame était fervente. Ayant appris l'existence du nouvel Ordre des Prêcheurs (Novum Ordinem Praedicatorum), elle désira en connaître les membres. Justement, frère Paul et un autre Frère, dans une tournée de prédication, vinrent à passer par là. Ils allèrent voir la recluse et l'entretinrent, comme font nos Frères, des choses de Dieu. Elle leur demanda de quel ordre ils étaient. Ils répondirent qu'ils étaient de l'Ordre des Prêcheurs. Et elle, voyant qu'ils étaient jeunes et beaux et correctement vêtus (juvenes, et pulchros et in honesto habitu), pensa qu'ils ne pourraient pas, en courant le monde, garder longtemps la continence. Mais la nuit d'après, elle eut un songe : la Vierge était devant elle, qui lui disait d'une voix courroucée: "Comme tu m'as offensée, hier! Crois-tu donc que je ne puisse protéger (custodire) mes jeunes serviteurs qui parcourent le monde pour le salut des âmes? Afin que tu saches que je les protège tout spécialement, vois, je te les montre, ceux que hier tu as méprisés" (ecce, ostendo, quos heri contempsisti). Et levant son manteau (Et ellevans pallium), elle lui montra une grande multitude de Frères (multitudinem Fratrum magnam) et dans le nombre, ceux que la recluse avait critiqués la veille. La recluse, édifiée à cette vue, aima de ce jour les Frères de tout son cœur, et c'est d'elle-même que l'ordre tient ce récit ${ }^{90}$.

Cet épisode, qui pourrait paraître redondant au regard du récit de Césaire de Heisterbach, ne constitue pas un simple transfert d'exemplum d'un ordre à l'autre. Il apporte des éléments nouveaux, adaptés à la spécificité des Ordres mendiants. La question de la clôture, en particulier, se trouve ici posée de façon sarcastique. Le fait que des religieux, jeunes de surcroît, soient en contact direct avec des laïcs (et avec la population des villes en général), semble à la recluse foncièrement incompatible avec le respect de leurs vœux, notamment celui de chasteté. C'est donc la conception même que les uns et les autres se font de la clôture qui est ici en jeu. L'adepte de la réclusion extrême, qui conçoit sa cellule comme l'espace immobile et personnel de sa pénitence, reproche aux Frères Prêcheurs l'abolition de la clôture tangible. Elle ne perçoit pas (car 
elle ne conçoit pas) la notion de "clôture intérieure " chère aux Mendiants qui leur permet précisément d'être mobiles, de s'impliquer dans le Monde, sans pour autant se compromettre avec lui. Visiblement, la recluse ne juge les Dominicains qu'à l'aune du modèle monastique. Le portrait de cette "emmurée", présentée comme curieuse et médisante (péchés caractéristiques de la gente féminine), reprend le topos de la recluse $^{91}$. Tout le paradoxe de ces femmes, laïques ou religieuses, réside en effet dans le choix d'une pénitence solitaire "en marge " (elles installent généralement leur reclusoir contre les murs des villes ou des églises, ou bien aux portes des murailles) suscitant en retour un pôle fort d'attraction sociale autour de leur cellule. La recluse devient alors le centre d'un lieu d'échanges dans la mesure où elle dépend entièrement de l'extérieur pour sa survie, et qu'elle dispense en contre-partie vers l'extérieur des conseils spirituels (ou des commérages, selon ses détracteurs misogynes!), son ascétisme lui conférant une auréole de sainteté.

La figure même de la recluse (ainsi que ses réactions face aux Frères Prêcheurs), pose donc de façon aiguë la question du ou des rôles de la clôture : définition d'un espace de pénitence ? enceinte d'une vie monacale stable et collective ? îlot de référence au sein de la société des laïcs? ou frontières intérieures de l'engagement religieux? Les Dominicains ayant opté pour la dernière définition, leur positionnement dans le corps social fait problème. La Vierge est alors appelée à la rescousse, comme pour pallier, grâce à sa figure englobante, l'évanouissement de la clôture matérielle. C'est son pallium, membrane textile virginale, qui garde (custodire) les Frères, c'est-à-dire qui les prémunit contre les péchés du Monde, en particulier contre le péché de chair. Le large manteau, en rassemblant en un même lieu les membres de l'ordre, offre également l'image idéale de la congregatio (au sens premier de «troupeau»), illisible au niveau du corps social puisque les Frères, itinérants, parcourent le Monde deux par deux.

Vierge au manteau dissimulant sous son pallium un ordre religieux, monastique ou mendiant, ne peut donc être assimilée a priori à une Vierge de Miséricorde : la fonction du manteau marial s'avère ici foncièrement polysémique et ne peut se réduire à l'unique protection maternelle venant tempérer la colère masculine du Fils divin envers les hommes de ce bas monde.

Contrairement à une idée reçue, tous les ordres religieux, au Moyen Âge, ne se sont pas blottis, indistinctement, sous le manteau de la Vierge. À cet égard, les absents nous en apprennent autant que les présents. En adoptant une démarche transversale et comparatiste, il apparaît en effet que ce sont les religieux se réclamant d'un idéal de gouvernement résolument décentralisé (à savoir les Cisterciens) qui mirent au point la représentation, aussi bien dans les textes que dans les images. Un lien fondamental existe donc entre l'agencement institutionnel interne à l'ordo et cette membrane textile externe qui vient enserrer les moines. Il semble alors que l'idée d'un pouvoir sans caput (c'est-à-dire d'un pouvoir partagé et donc dépersonnalisé) soit ressentie comme une «faiblesse indicible » qui nécessite le recours à un cadre institutionnel autre, fort et incontestable : l'Ecclesia. Celle-ci, en incorporant (au sens premier) l'ordo, lui confère du même coup sa cohérence substantielle, la Caritas.

Cependant, dans les ordres religieux (sans doute encore davantage que dans tout autre type d'organisation sociale), l'Institutionnel touche à la question de l'Origine, et en particulier à celle du Père fondateur. Là encore, les ordres ayant connu un problème de positionnement de la figure du fondateur (les Cisterciens, les Chartreux et dans une moindre mesure les Dominicains) ont adopté la figure emblématique de la Vierge- 
Église. L'enceinte sacrée et corporéisée que forme le manteau marial vient alors pallier le «flottement» du noyau interne. En d'autres termes, lorsque les liens de parenté spirituelle entre le Père et les fils manquent d'évidence, la Mère par excellence s'impose. A contrario, la Vierge ne peut visiblement pas cohabiter avec Benoît ou François, modèles absolus de leurs disciples: malgré sa capacité extraordinaire de dilatation, il demeure impossible à la Mère d'inclure dans ses limites un Père fondateur au fort pouvoir fédérateur.

Mais Marie n'incarne pas n'importe quelle Mater puisqu'elle instaure, par sa position charnière entre l'au-delà et l'ici-bas, une dialectique entre parenté divine et parenté spirituelle. En tant précisément que Mère du Fils, elle fonde la communauté des Chrétiens, fils de Dieu et frères du Christ. Les ordres religieux, micro-sociétés parfaites et idéales, qui exaltent les relations exclusivement spirituelles entre leurs membres, occupent naturellement, plus que tout autre familia entachée par la parenté charnelle, « la chambre de Marie ».

81 Néanmoins, la Vierge ne constitue pas uniquement le rempart périphérique de 1'Ordo Tabernaculum du Verbe, elle cristallise également de l'intérieur l'ordre sans tête afin que les membres de la fraternitas participent de l'Incarné. Ainsi, elle transfert l'idée de corps mystique sacramentel de l'Église vers l'Ordo. Les distinctions de genre et les classifications statutaires, instituées sur terre pour gérer un monde imparfait, sont alors amenées à disparaître lorsque les moines s'élèvent jusqu'au réceptacle du Verbe.

Néanmoins, le manteau de Marie n'échappe pas pour autant à l'histoire. Outre ses fonctions "anthropologico-institutionnelles " conférant à une congregatio un centre divin et une périphérie, il se charge d'une sémantique particulière lorsqu'il s'applique non plus aux moines mais aux Dominicains. Il donne alors à voir la réunion idéale des Frères itinérants éclatés aux quatre coins du champ missionnaire; il exprime aussi la notion de clôture intériorisée: non plus celle qui sépare, en les regroupant, les religieux du monde laïque, mais celle qui, silencieusement et invisiblement, préserve les vœux du Frère Prêcheur.

La Vierge au manteau appliquée aux ordres religieux nous parle donc autant d'élection que de protection; autant de structures internes que d'enveloppe duveteuse. Elle dessine en creux le visage d'un Père spirituel mal défini ; elle laisse également deviner toute la difficulté qu'a eue le Moyen Âge à penser en image le pouvoir collégial sans pour autant sacrifier l'Unité.

\section{NOTES}

1. Cet article reprend la matière d'un des chapitres de ma thèse consacrée plus généralement aux représentations des ordres religieux au Moyen Âge: Corps-famille-réseau: trois paradigmes pour penser en images les ordres religieux (XII ${ }^{e}-\mathrm{XV}^{e}$ s.), sous la direction de J.-Cl. Schmitt, EHESS, 2001.

2. P. Perdrizet, La Vierge de Miséricorde, étude d'un thème iconographique, Paris, 1908. Sur ce thème iconographique, voir également L. Réau, Iconographie de l'art chrétien, II, 2, pp.112-120; M. Vloberg, La Vierge, notre médiatrice, Grenoble, Arthaud, 1938 (en particulier pp.109-129); 
C. Belting-Ihm, Sub matris tutela. Untersuchungen zur Vorgeschichte der Schutzmantelmandonna, Heidelberg, 1976 ; N. J. Hubbard, Sub pallio. the sources and development of the Iconography of the Virgin of Mercy, Evanston, 1984 (thèse). Sur ce thème appliqué aux bannières des villes italiennes (gonfalons), voir D. Arasse, «Entre dévotion et culture: fonctions de l'image religieuse au $\mathrm{XV}^{\mathrm{e}}$ siècle ", Faire croire, Modalités de la diffusion et de la réception des messages religieux du XII ${ }^{e}$ au $X V^{e}$ siècle, Table ronde organisée par l'EFR en collaboration avec l'Institut d'Histoire Médiévale de l'Université de Padoue, Rome, 22-23 juin 1979, Rome, EFR, 1981, pp. 131-146.

3. Sur la distinction entre motif et thème iconographiques, voir J. Baschet, "Inventivité et sérialité des images médiévales, pour une approche iconographique élargie », Annales HSS, janv.fév. 1996, n 1, pp. 93-133, et notamment p. 114.

4. Caesarius von Heisterbach, Dialogus Miraculorum, éd. J. Strange, Cologne-Bonn-Bruxelles, 1851-57 (2 vol.).

5. La traduction francaise reprise ici est celle de Perdrizet, op. cit., pp. 21-22. Pour le texte latin, cf. éd. citée, Cologne, 1851, t. 11, p. 79.

6. Les ordres mendiants, créés depuis peu, ne sont pas encore intégrés à ce récit rédigé entre 1217 et 1222.

7. Sur ce thème qui mériterait une étude à la fois globale et en profondeur, voir D. Russo, « La cour céleste dans l'iconographie italienne des derniers siècles du Moyen Âge ", Le peuple des saints, croyance et dévotions en Provence et Comtat Venaissin des origines à la fin du Moyen Âge, Mémoires de l'Académie de Vaucluse, VI, 1985, pp. 287-299.

8. Sur les manuscrits de la Cité de Dieu voir A. de Laborde, Les manuscrits à peinture de la Cité de Dieu de saint Augustin, Paris, 1909.

9. Sur le classement des saints par catégories au Moyen Âge, voir A. Boureau, La Légende Dorée, le système narratif de Jacques de Voragine,Paris, Cerf, 1984, pp. 32-34.

10. Sur ce tableau, voir notamment $Y$. Le Pichon, Le mystère du couronnement de la Vierge, Paris, 1982.

11. Notre image textuelle s'éloigne en effet des représentations de la Vierge de Miséricorde dont le manteau arrête ou dévie, tel un bouclier, les flèches de la colère divine et/ou de la peste. Sur ces images, voir M. Vloberg, La Vierge, notre médiatrice, op. cit., pp. 120-129; et P. Perdrizet, La Vierge de Miséricorde, op. cit., pp. 126-136.

12. Les métaphores les plus fréquemment utilisées au Moyen Âge pour désigner Marie sont regroupées dans A. Blaise, Le vocabulaire latin des principaux thèmes liturgiques, Turnhout, Brepols, 1966, pp. 346-352.

13. Il faut remarquer que l'intérieur du manteau de Marie est souvent fourré de vair, ce qui exprime bien sûr la magnificence du personnage mais induit aussi l'idée d'un nid duveteux.

14. Fovere signifie "chauffer", mais aussi "couver", "réchauffer sur son sein ", "garder soigneusement », " protéger ».

15. Cf. E. Dumoutet, Le désir de voir l'hostie, Paris, 1926.

16. Sur les sceaux cisterciens liés d'une façon ou d'une autre à la Vierge, voir P. Bony, "An introduction to the study of cistercian seals : the Virgin as Mediatrix then Protectrix on the Seals of Cistercian Abbeys ", Cistercian Studies Series, n 89, Cistercian Publications, Kalamzoo, 1987, pp. 201-240. Sur l'intérêt des sceaux en général comme sources historiques, je renvoie principalement aux travaux de M. Pastoureau, en particulier Les sceaux, TSMAO, fasc. 36, Turnhout, Brepols, 1981, et "Les sceaux et la fonction sociale des images ", L'image, fonctions et usages des images dans l'Occident médiéval,(dir. J.-Cl. Schmitt et J. Baschet), Cahiers du Léopard d'Or, 5, Paris, 1996, pp. 275-308.

17. M. Pastoureau, Figures et couleurs, étude sur la symbolique et la sensibilité médiévales, Paris, Le Léopard d'Or, 1986, p. 76.

18. Pour un aperçu de la diversité des sceaux en milieu monastique, voir H. Collin, Lotharingia, archives lorraines d'archéologie, d'art et d'histoire, t. 1, Nancy, 1988, pp. 246-272 (« Le monde des 
moines et des nonnes ») ; S. Ricci (a cura di), Il sigillo nella storia e nella cultura, catalogo della mostra documentaria, Rome, Jouvence, 1985, pp. 182-198 (sceaux des ordres religieux, militaires et hospitaliers).

19. Sur ce sceau, voir H. Collin, Lotharingia, op. cit., p. 262, fig. 273 ; et L. Pressouyre et T. N. Kinder (dir.), Saint Bernard et le monde cistercien, catalogue de l'exposition présentée à l'occasion du $9^{\mathrm{e}}$ centenaire de la naissance de saint Bernard (Paris, Conciergerie, 1990), CNMHS/SAND, 1990, $\mathrm{n}^{\circ} 197 \mathrm{du}$ catalogue.

20. Le statut de ces inscriptions sigillaires disposées en rond est étudié par M. Pastoureau, «Un texte-image : l'écriture circulaire », Couleurs, images, symboles, études d'histoire et d anthropologie, Paris, Le Léopard d'Or, 1989, pp. 125-137.

21. P. Michaud-Quantin, Universitas, expressions du mouvement communautaire dans le Moyen Âge latin,Paris, Vrin, 1970.

22. Op. cit. dans la note ci-dessus.

23. Sur ce sceau, voir P. Perdrizet, La Vierge de Miséricorde, op. cit., p. 27, fig. 1 ; P.-Ch. Cahier, Les caractéristiques des saints dans l'art populaire, 1, Saint-Julien, Éd. de Sancey, 1981, p. 298.

24. Pour le rôle du définitoire, cf. M. Pacaut, Les Moines Blancs, histoire de l'ordre de Cîteaux, Paris, Fayard, 1993, chapitre V, («Le jeu des structures»), en particulier pp. 197-198. Voir également J. B. Van Damme, « Genèse des Instituta Generalis Capituli », Cîteaux, Commentarii Cistercienses, 1961, pp. 28-60. Sur le chapitre général comme mode de fonctionnement, voir « Les origines religieuses des techniques électorales et délibératives modernes », Revue Internationale d'Histoire politique et constitutionnelle, 1953, pp.108-148. Sur l'adoption du chapitre général par les autres ordres religieux, voir J. Dalarun, François d'Assise ou le pouvoir en question, principes et modalités du gouvernement dans l'ordre des frères mineurs,De Bœck Université, Paris/Bruxelles, 1999, en particulier pp. 42-46 (« À titre de comparaison »).

25. Cf. A. H. Bredero, Cluny et Cîteaux au XII siècle : l'histoire d'une controverse monastique, Amsterdam, Maarssens, 1986.

26. Il ne faut cependant pas oublier que même chez les Cisterciens, à côté du sceau de l'abbaye, exprimant l'autorité consensuelle et collective du conventus, existait le sceau de l'Abbé en personne, souvent issu des rangs de l'aristocratie. Ce dernier " cachet » était en général marqué du poing tenant la crosse (signe de l'autorité suprême) et des armoiries personnelles du supérieur. Alors que l'usage du premier sceau perdurait au-delà de la succession des abbés (incarnant par-là même la pérennité du pouvoir partagé et l'identité de la Maison), le second sceau n'était utilisé, bien sûr, que le strict temps d'un abbatiat. Ces remarques prouvent qu'audelà de l'iconographie des sceaux, les modalités de leur usage sont également signifiantes. Sur le pouvoir effectif de l'Abbé de Cîteaux dans l'ordre cistercien, voir J. B. Van Damme, « Les pouvoirs de l'Abbé de Cîteaux aux XII et XIII ${ }^{\mathrm{e}}$ siècles », Analecta Sacri Ordinis Cisterciensis, 1983, pp. 92-110. Sur le sceau particulier de saint Bernard et le mythe de la vera effigies, voir J.-Cl. Schmitt, «Saint Bernard et son image ", Bernard de Clairvaux (1090-1153), Histoire, Mentalités, Spiritualité, Paris, SC 380, 1992, pp. 639-657.

27. Le prologue de la Carta Caritatis énonce mieux que tout autre document cette "charitéciment » qui soude les membres de l'ordre malgré la dispersion géographique des maisons et des moines: In hoc ergo decreto praedicti fratres mutuae pacis futurum praecaventes naufragium, elucidaverunt et statuerunt suisque posteris reliquerunt, quo pacto quove modo, immo qua caritate monachi eorum per abbatias diversis mundi partibus corporibus divisi animis indissolubiliter conglutinarentur, Cîteaux, Documents primitifs, Commentarii Cistercienses (Textes et Documents), 1988, p. 58. Sur le concept d'unanimité qui a profondément marqué l'idéal primitif de l'ordre, voir J.-B. Auberger, L'unanimité cistercienne primitive (1098-1153) : mythe ou réalité ?, Commentarii Cistercienses, Achel, 1986. À compléter par Unanimité et diversité cisterciennes, Filiations-Réseaux, Relectures du XII ${ }^{e}$ au XVII ${ }^{e}$ siècle, Actes du IV e colloque international du CERCOR, Dijon, 23-25 sept. 1998, Publications de l'Université de Saint-Étienne (CERCOR, Travaux et recherches, XII), 2000. 
L'extension de l'ordre vécue par les moines cisterciens comme une séparation de corps mais non d'esprit est analysée dans le très bel article de J. Regnard, "Pour une spiritualité du lieu ", Collectanea Cisterciensia, t. 61, 1999, 1, pp. 22-39.

28. Sur ce document, cf. Lotharingia, op. cit., pp. 263-264.

29. Pour avoir une première vue d'ensemble des différents types de sceaux urbains, on peut consulter: P. Delaroche, Trésor de numismatique, 15, les sceaux des communes, des communautés, évêques, abbés et barons, Paris, Rittner et Goupil, 1837 ; B. Bedos, Les sceaux des villes, Corpus des sceaux français du Moyen Âge, t. I, Paris, Archives Nationales, 1980 ; ainsi que l'étude de C. de Merindol, « Iconographie du sceau de ville en France à l'époque médiévale et religion civique », La religion civique à l'époque médiévale et moderne, collect. de l'EFR 213, Rome, 1995, pp. 415-428.

30. Tous les sceaux de villes n'optent pas cependant pour la représentation de cette collégialité. Un monument particulièrement reconnaissable (souvent lié au pouvoir de l'évêque, comme la cathédrale Saint-Maurice à Vienne), peut incarner à lui-seul la commune ; de même, l'emblème d'une corporation puissante ayant participé à l'octroi de privilèges (comme par exemple celle des «Marchands de l'eau » à Paris) peut également symboliser la commune tout entière.

31. Sur les institutions de l'ordre cistercien, voir essentiellement J. B. Mahn, L'Ordre cistercien et son gouvernement des origines au milieu du XIIle siècle (1098-1265), Paris, 1945. À compléter par B. Lucet, La codification cistercienne de 1202 et son évolution ultérieure, Rome, 1964.

32. Sur cette image, voir L. Pressouyre et T. N. Kinder (dir.), Saint Bernard et le monde cistercien, op. cit., notice 198 du catalogue.

33. Sur l'institution des convers dans l'ordre cistercien, voir J. Dubois, « L'institution des convers au XII ${ }^{\mathrm{e}}$ siècle. Forme de la vie monastique propre aux laïcs ", I laici nella societas christiana'dei secoli XI e XII, Atti della terza settimana internazionale di studio, Mendola, 21-27 Août 1965, Milan, 1968, pp. 183-261.

34. Cet imprimeur, d'origine suisse, a été appelé à Dijon par l'abbé réformateur de Cîteaux Jean de Circey. À partir de 1488, il imprima pour la maison-mère des collections de textes cisterciens, normatifs et spirituels, jusqu'alors manuscrits, qui furent ainsi diffusés dans les différentes maison du réseau monastique. Sur le rôle de Jean de Cirey dans l'ordre, voir M. Pacaut, Les Moines Blancs, histoire de l'Ordre de Citeaux,Paris, fayard, 1993,pp. 301-304.

35. Voir K. E. Boressen, Subordination et équivalence. Nature et rôle de la femme d'après Augustin et Thomas d'Aquin, Oslo-Paris, 1968. Voir également Chr. Klapisch-Zuber, "Masculin/Féminin », Dictionnaire raisonné de l'Occident Médiéval, (dir. J. Le Goff et J.-Cl. Schmitt), Paris, Fayard, 1999, pp. 655-668. On trouvera encore d'autres jalons de ce phénomène culturel dans P. L'HermiteLeclercq, L'Église et les femmes dans l'Occident chrétien des origines à la fin du Moyen Âge, Turnhout, Brepols, 1997.

36. Cf. J.-Cl. Schmitt, «Clercs et Laïcs » in Dictionnaire raisonné de l'Occident médiéval, op. cit., pp. 214229.

37. J.-Cl. Schmitt, La raison des gestes dans l'Occident médiéval,Paris, Gallimard, 1990, p. 333.

38. Sur ce thème et ses multiples développements dans l'art, voir M. Vloberg, La Vierge, notre médiatrice, Grenoble, 1938. Pour une approche essentiellement théologique, consulter E. Druwe, «La médiation universelle de Marie », MARIA, Études sur la sainte Vierge, I, éd. H. Du Manoir, Paris, 1949, pp. 418-572 ; J. Bur, «La médiation de Marie, essai de synthèse spéculative », MARIA, VI, 1961, pp. 471-512. Sur un plan plus dévotionnel et liturgique (en particulier l'histoire de la prière Sub tuum..), cf. J. Galot, « L'intercession de Marie », MARIA, VI, pp. 513-550.

39. Sur les imbrications entre parenté spirituelle, parenté charnelle et organisation des structures sociales au Moyen Âge, je renvoie aux travaux fondamentaux d'A. Guerreau-Jalabert, en particulier "Sur les structures de parenté dans l'Europe médiévale », Annales E.S.C, 36, 1981, pp. 1028-1049; « Spiritus et Caritas : le baptême dans la société médiévale », F. Héritier-Augé et E. Copet-Rougier (dir.), La parenté spirituelle, Paris, 1995, pp. 133-203 ; «L'arbre de Jessé et l'ordre chrétien de la parenté », Le culte de la Vierge dans la société médiévale, dir. D. Iogna-Prat, E. Palazzo 
et D. Russo, Paris, 1996, pp.137-170. Le travail de K.E. Börresen, bien que de portée moins ambitieuse, apporte des éléments au débat: Anthropologie médiévale et théologie mariale, Oslo, 1971. 40. On pourra se reporter entre autres à l'ouvrage très complet d'H. de Lubac, Méditation sur l'Église, Paris, Aubier, 1954 (en particulier chapitre I, «Parenté des Chrétiens » et chapitre IX, "L'Église et la Vierge Marie»). Voir également les analyses de Th. Koehler, "Maternité spirituelle, maternité mystique », MARIA, VI, 1961, pp. 551-638. Sur les fondements patristiques, voir plus spécialement K. Delahaye, Ecclesia Mater chez les Pères des trois premiers siècles, Unam Sanctam, 46, Paris, Cerf, 1964.

41. Cf. Isaac de l'Étoile, Sermons, III, SC 339, Paris, Cerf, 1987.

42. Idem, Ibidem, Sermon 51, 7-8, pp. 202-205.

43. Ce phénomène s'avère particulièrement sensible dans les statues cultuelles que sont les Vierges ouvrantes habitées, dans leur vide intérieur, par le Fils ou la Trinité. Celle exposée dans l'église Saint-Matthieu à Morlaix (c. 1390) donne à voir, lorsqu'elle est fermée, une Mater Omnium et révèle, lorsqu'elle est ouverte, un trône de grâce.

44. «Premier sermon pour l'Assomption ", (2) Guerric d'Igny, Sermons, II, SC 202, Paris, Cerf, 1973, pp. 416-417.

45. Guerric d'Igny, Sermons, 1, SC 166, Paris, Cerf, 1970, pp. 178-179.

46. Isaïe, 54, 1-3.

47. Sur ce tableau, qui est très souvent attribué à tort à Jean Prévost (ou Provost), voir Françoise Baliguand, «Jean Bellegambe au musée de Douai », Revue du Nord, t. LXXIV, n² 297-298, p. 760-762. Je remercie l'auteur de l'article, conservateur au Musée de Douai, d'avoir bien voulu me faire part de ses recherches sur ce panneau.

48. Guerric d'Igny, "Premier sermon pour l'Assomption", 4, SC 202, pp. 420-423: Et nunc siquidem habitamus adiutorio matris Altissimi; protectione ipsius commoramur tamquam sub umbra alarum eius : et postmodum consortio gloriae ipsius tamquam sinu ipsius confovebimur.

49. Voir J. Baschet, Le sein du père. Abraham et la paternité dans l'Occident médiéval, Paris, Gallimard, 2000.

50. Guerric d'Igny, ibidem, pp. 422-423: Nullatenus autem credideris maioris esse felicitatis et gloriae habitare sinu Abrahae, quam sinu Mariae, cum thronum suum ea posuerit Rex Gloriae.

51. Cf. D. Y. Gourdel, « Le culte de la Très Sainte Vierge dans l'histoire de l'Ordre des Chartreux ", MARIA, II, Paris, 1952, pp. 625-678 (avec des réserves).

52. Sur ce tableau, voir Verzeichnis der Gemälde des Städtischen Museums Wallraf-Richartz zu Köln, Cologne, 1903, p. 35, notice 157. Consulter également F. G. Zehnder, Gotische MalereiKöln, Altkolner Bilder von 1300-1550, Cologne, 1989, pp. 82-83; et Die Kölner Kartause um 1500, Kölnisches Stadtmuseum, Cologne,1991, notice du catalogue 5,11, pp. 179-181.

53. La chartreuse de Cologne a fait l'objet d'une thèse de troisième cycle: G. Chaix, Réforme et contre-réforme catholique. Recherches sur la chartreuse de Cologne au XVI siècle, ed. Analecta Cartusiana, 80, Salzbourg, 1981 (3 t. en 3 vol.).

54. Cf. op. cit. dans la note précédente, pp. 6-7.

55. Sur les convers dans l'ordre cartusien, voir D. Le Blevec, « Les convers de Chartreuse d'après les textes législatifs de l'ordre, XII ${ }^{\mathrm{e}} \mathrm{XIII}{ }^{\mathrm{e}}$ siècles", Les mouvances laïques des ordres religieux, III ${ }^{\mathrm{e}}$ colloque international du CERCOR, Publications de l'Université de Saint-Étienne, 1996, pp. 67-79.

56. Un petit détail, le livre de prière, permettant de rattacher les membres de la famille charnelle (celle des donateurs) à la communauté spirituelle des moines, induit néanmoins un léger déséquilibre : un livre est en effet tenu et par le plus âgé des chartreux, et par le plus jeune des laïcs (chiasme intéressant).

57. Ici, la spiritualité du Rosaire semble entrer en ligne de compte puisque l'enfant Jésus joue avec un chapelet et que les spirales des deux crosses épiscopales contiennent des motifs qui glorifient la maternité virginale : à gauche, une rose ; à droite, l'Annonciation. 
58. Ce rêve est relaté dans la Vita S. Hugonis Gratianopol. par Guigues I ${ }^{\text {er }}$, ed. P. L. 153, col. 769-770 pour la vision des étoiles.

59. Sur l'iconographie d'Hugues de Lincoln, L. Réau, III, 2, 1958, pp. 665-666.

60. Sur la paternité de Bruno, consulter G. Posada, Der Heilige Bruno, Vater des Kartaüser : ein Sohn der Stadt Köln, Cologne, Wienard Verlag, 1987.

61. La première vie de saint Bruno paraît à Cologne en 1516 : P. Blomevenna, Vita sancti Brunonis (sl, sn, sd), Cologne, bibliothèque universitaire, cote $\mathrm{AD} 359$.

62. P.L. 153, col. 768-772.

63. Consuetudines Cartusiae, ed. Paris, Cerf (S.C. 313), 1984.

64. Bruno tend à devenir au $\mathrm{XV}^{\mathrm{e}}$ siècle le «saint civique » de Cologne, sa ville natale. Sur ce phénomène, voir G. Chaix, « La gloire de Dieu, I'honneur de Bruno et la sainteté de Cologne, les tâches de la chartreuse Sainte Barbe », R. Wagner et U. Bock, Die Kölner Kartause um 1500, Stadt Köln, Kölnisches Stadtmuseum, 1991, pp. 271-274.

65. Le fait est patent dans l'historiographie camaldule qui lie fortement Romuald au locus désertique initial.

66. Étienne Harding, Carta Caritatis, Citeaux, Documents primitifs, Commentarii Cistercienses (Textes et Documents, 1), 1988, pp. 55-105.

67. La construction de l'image hagiographique de Bernard a été finement analysée par A. H. Bredero dans Bernard de Clairvaux, culte et histoire, Turnhout, Brepols, 1998 ( $1^{\text {re }}$ éd. en néerlandais, Kampen, 1993).

68. Sur Bernard Père spirituel de l'ordre cistercien, voir le bel article de J. Leclercq, «La Paternité de saint Bernard et les débuts de l'ordre cistercien ", Revue Bénédictine, CIII, n³-4, 1993, p. $445-481$.

69. Faut-il y voir ici la marque de la subordination des moniales au versant masculin de l'Ordre?

70. Cf. Fr. Baliguand, «Jean Bellegambe au Musée de Douai », art. cit., pp. 760-762.

71. Il suffit pour s'en convaincre de lire Bernard de Clairvaux, À la louange de la Vierge Mère, Paris, Cerf (S.C. 390), 1993. Voir également J. Leclercq, « Saint Bernard et la dévotion médiévale envers Marie », R.A.M., 30, 1954, pp. 361-375.

72. Ce rêve se trouve également dans La Légende des Trois Compagnons, 63, achevée en 1246. Cf. Saint François d'Assise, Documents, Paris, Éd. franciscaines, 1968, pp. 854-855. Pour la version latine, se reporter à Legenda Trium Sociorum, Fontes Francescani, a cura di E. Menesto et S. Brufani, Assise, Éd. Porziuncola, 1995, p. 1436.

73. Saint François d'Assise, Documents, pp. 342-343. Pour le texte latin, cf. A.F., X, pp. 144-145.

74. L'expression columbae domesticae renvoie d'ailleurs davantage, à mes yeux, à Marthe qu'à Marie

75. Sur les prophéties de François, voir N. Bériou, «Saint François prophète de son ordre dans les sermons du XIII ${ }^{\mathrm{e}}$ siècle », MEFR Moyen Âge/Temps Modernes, 102, 1990, p. 535-553.

76. Cette impression est confirmée par le passage qui précède immédiatement la vision : «Le bienheureux prévoyait qu'entre ses fils eux-mêmes pouvaient naître des difficultés au détriment de la paix et de l'unité; il tremblait à la pensée de voir se lever parmi eux, comme il arrive souvent parmi les êtres de choix, des récalcitrants obstinés dans leurs propres vues, prompts à la révolte et prêts à y entrainer les autres, Saint François d'Assise, Documents, op. cit., pp. 341-342.

77. Voir sur cette question J. Dalarun, François d'Assise, un passage, femmes et féminité dans les écrits et les légendes franciscaines,Arles, Actes-Sud, 1997.

78. Cf. A. Cabassut, "Une dévotion médiévale peu connue : la dévotion à Jésus Notre Mère ", R.A.M., avril-déc., 1949, pp. 234-245 ; et surtout C. Bynum, Jesus as Mother, Studies the spirituality of the High Middle Ages, Berkeley/Los Angeles/London, 1982, et plus particulièrement ici son article "Jesus as Mother and Abbot as Mother in twelfth century cistercian writing", Harvard Theological Review, 70, 1977, pp. 257-284. 
79. Cette incapacité à regrouper et à gérer son ordre est également sensible dans la Légende des Trois Compagnons: ... Mihi autem Dominus per misÉricordiam saam dedit et dabit filios multos quos protegere mea virtute non potero..., Fontes Franciscani, p. 1436.

80. Saint Francois d'Assise, Documents, pp. 342-343.

81. J. Dalarun, François d'Assise, un passage, op. cit., p. 226.

82. Cf. D. P. Salmon, L'abbé dans la tradition monastique, contribution à l'histoire du caractère perpétuel des Supérieurs religieux en Occident,Paris, 1962.

83. Sur ce phénomène d'historiographie collective, je me permets de renvoyer au chapitre concernant les « arbres ordo » des Frères Prêcheurs, dans la thèse citée en note 1.

84. Voir sur ce manuscrit S. Magnolia, "La miniatura ", La chiesa e il convento di san Marco di Firenze, vol. II, Florence, 1990, pp.11-36. Et Painting and illuminationearly Renaissance, Florence, 1300-1450, New York, Metropolitan Museum of Art, 1994, pp. 334-338.

85. Cf. A. Duval, «La dévotion mariale dans l'ordre des frères Prêcheurs », MARIA, II, op. cit., 1952, pp. 739-782.

86. Thomas de Cantimpré, Bonum universale de proprietatibus apium, seu miracula et exempla memorabilia, Douai, 1605.

87. Cette traduction française s'appuie sur celle de H. Platelle, à laquelle je me suis permise ici d'apporter quelques modifications au regard du texte latin. Cf. Les exemples du Livre des Abeilles, présentation, trad. et commentaire par Henri Platelle, Brepols, 1997, pp. 125-126.

88. Thierry d'Apolda, Vita S. Dominici, A.S.S., Août, I, pp. 558-628 (p. 583 pour cette vision).

89. Gérard de Frachet, Vitae Fratrum Ord. Praed. necnon chronica ordinis ab anno 1203 usque 1254, ed. Reichert, MOPH, 1, Louvain, 1896.

90. Traduction française tirée de P. Perdrizet, La Vierge de Miséricorde., pp. 34-35. Cf. pour la version citée à la note ci-dessus, pp. 40-41. Le même récit, bien que sous une forme moins développée, est ensuite passé dans les Vies de saint Dominique par Barthélemy de Trente (in A.S.S., Août, 1, p. 561), et par Thierry d'Apolda (A.S.S., Août, 1, p. 583).

91. Sur les recluses au Moyen Âge, voir essentiellement les travaux de P. L'Hermite-Leclercq, «La vie quotidienne des recluses ", L'Histoire, 126, oct. 1989, pp. 30-37 ; « La prière de la recluse », Prier au Moyen Âge, pratiques et expériences ( $V^{e}-X V^{e}$ s.), Brepols, 1991, pp. 158-164.

\section{AUTEUR}

\section{DOMINIQUE DONADIEU-RIGAUT}

Université de Nantes 